\title{
ESTUDIO DE LAS TRANSFORMACIONES URBANAS DEL ÁREA CENTRAL DE BUCARAMANGA
}

Arquitecto José Alejandro Gómez*

Historiador Néstor José Rueda Gómez***

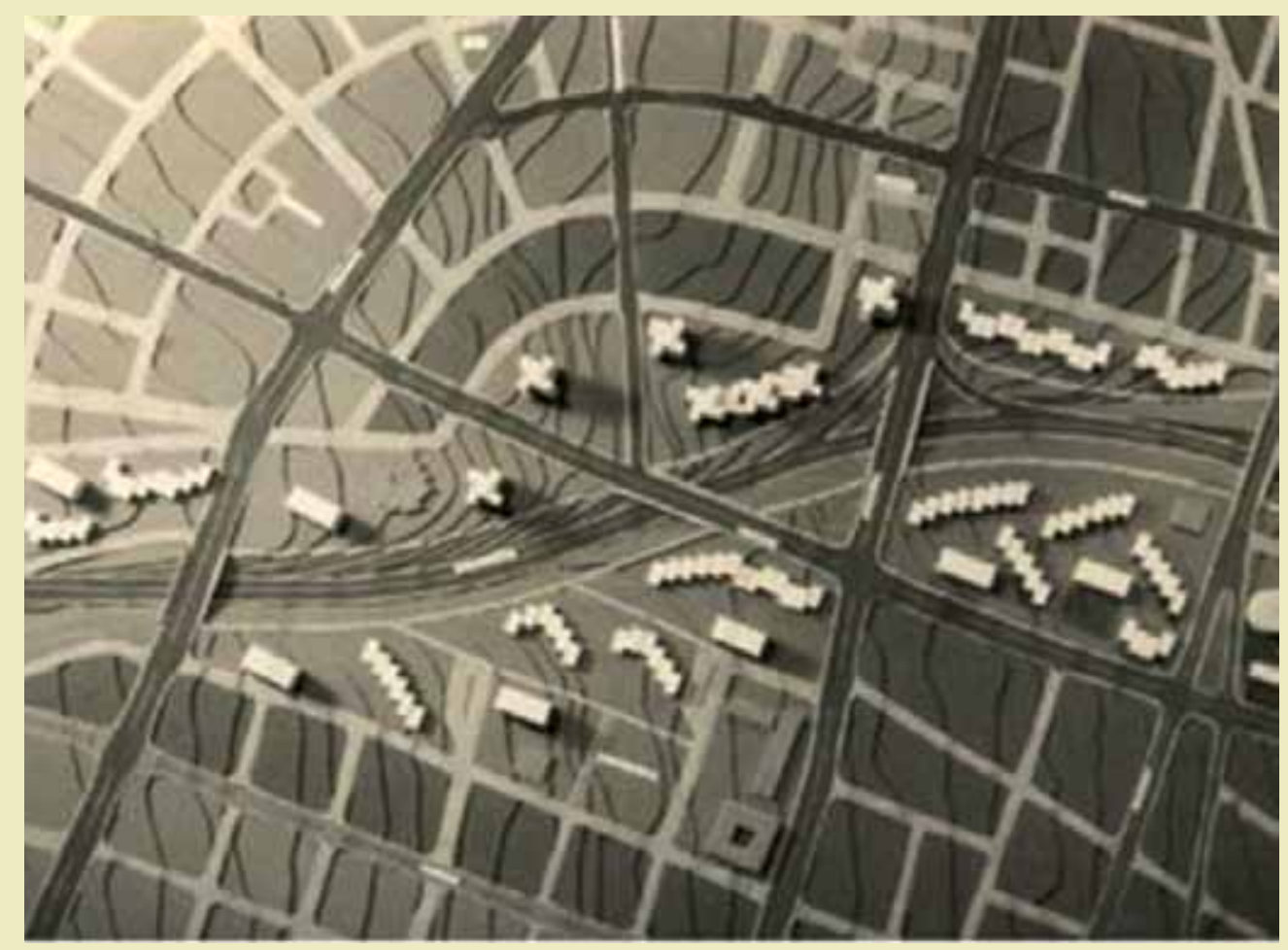

\section{RESUMEN}

El presente artículo de investigación es el producto del Proyecto presentado a la convocatoria interna de la universidad y financiado en su totalidad por la misma. A lo largo de las siguientes páginas se hará una exposición del trabajo desarrollado y de sus alcances. Es así mismo, una síntesis de un amplio documento que recoge un vasto trabajo de campo, así como de una ardua tarea de sistematización y digitalización de información tanto cuantitativa como gráfica.

\section{PALABRAS CLAVE}

Reforma urbana, conflictos urbanos, deterioro, espacio público. 


\section{ESTUDY OF THE URBAN TRANSORMATIONS OF THE CENTRAL AREA OF BUCARAMANGA}

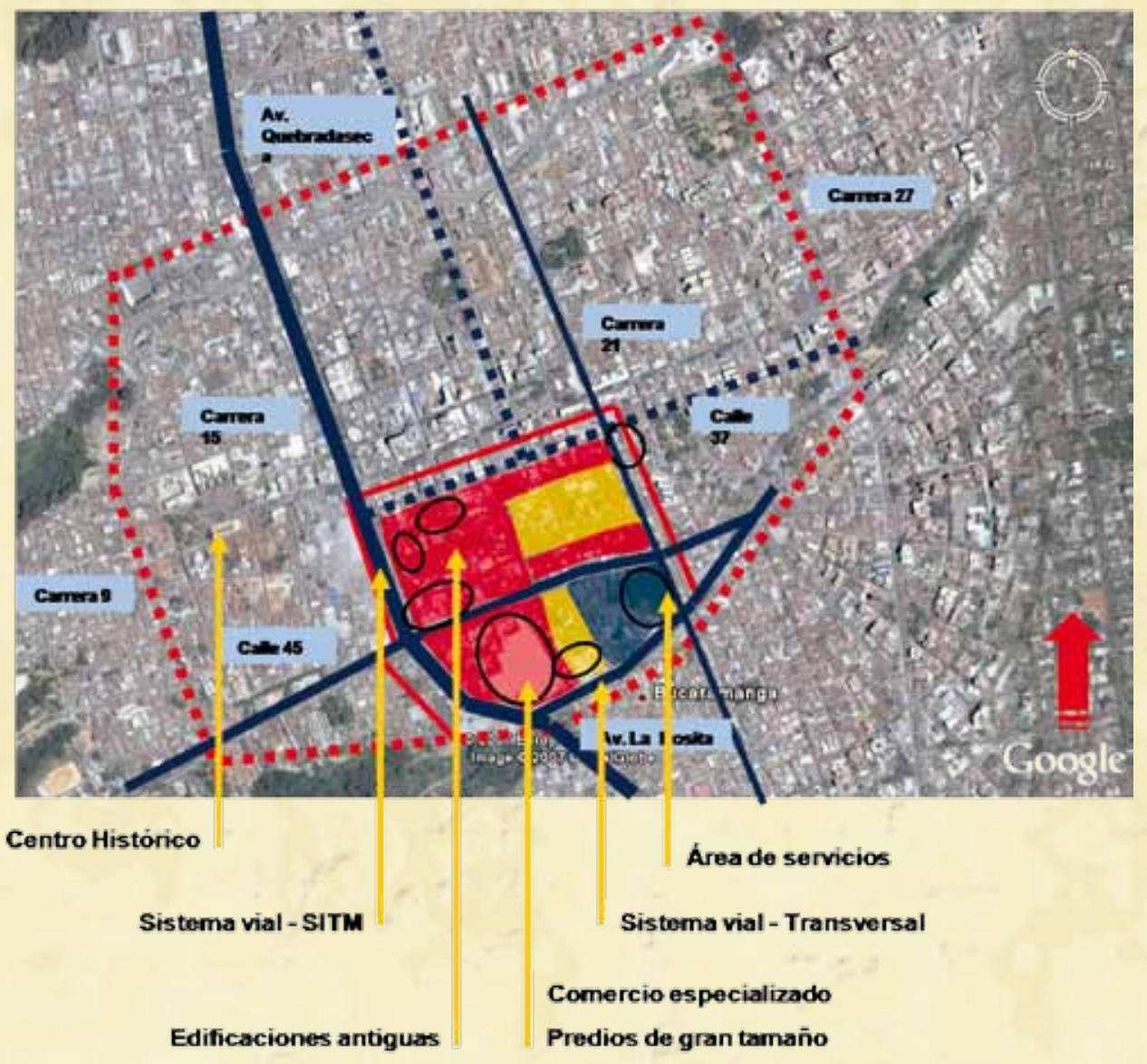

\section{ABSTRACT}

The present research article is the product of the project presented for the internal call of the university and financed totality by the same. Throughout the following pages an exhibition will be made about the developed work and its scope. It is also, a synthesis of a wide document that gathers a vast field work, as well as of an arduous task of systematization and digitalization of quantitative and graphical information.
Arquitecto, Universidad Santo Tomás, Bucaramanga Especialista en Planificación Urbana y Regional, Universidad de Buenos Aires, Argentina Docente Universidad Santo Tomás josealejandrogomez@hotmail.com

** Historiador, candidato a doctor en Régimen Jurídico y Ordenación de Territorio U.P.V. Valencia, España Director del Laboratorio de Investigaciones Urbanas LIU y Líder del Grupo de Investigaciones Facultad de Arquitectura USTA Bucaramanga. Nergoz80@hotmail.com Auxiliares: Semillero de investigación Facultad de Arquitectura.

Estudiantes colaboradores: Grupos de electiva y énfasis y los auxiliares: Angélica Patricia Echeverri Triana, Natalia Santos Villarreal, Montserrat Rueda Gómez, Gustavo José Bautista Moros 


\section{PROBLEMA}

Numerosas situaciones conflictivas se desarrollan en el área metropolitana más importante del nororiente colombiano, producto de la creciente complejidad de los fenómenos que acompañan el desarrollo urbano de un territorio que todavía no ha visto las bondades de los procesos de planificación. (Figura I)

El crecimiento expansivo de Bucaramanga, originado principalmente por el vertiginoso aumento demográfico, ha generado entre otros, un aprovechamiento poco eficiente del suelo, degradación de las áreas centrales, deseconomías urbanas, pérdida de tierras rurales, especulación en el valor de suelo, congestión vehicular, aumento en las distancias recorridas y del número de viajes intraurbanos, en tal sentido se planteó como necesaria la implantación de un sistema de transporte masivo, la ampliación y construcción de nuevas infraestructuras, equipamientos y redes de servicios públicos, lo que implica no solamente una solución a los problemas sectoriales, sino la generación de cambios sustanciales en las políticas urbanas y en la forma de apropiación y uso del territorio. (Foto I.)

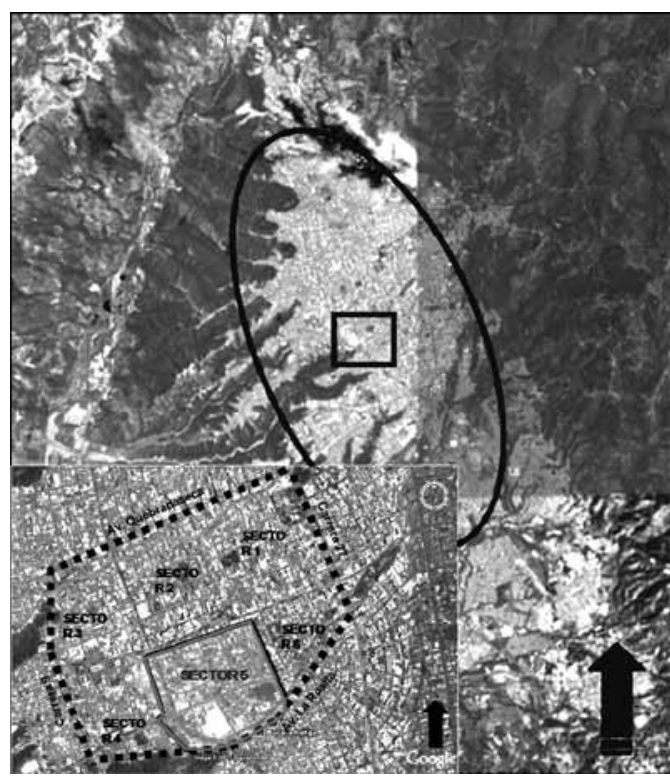

Figura 1. Localización general del área central

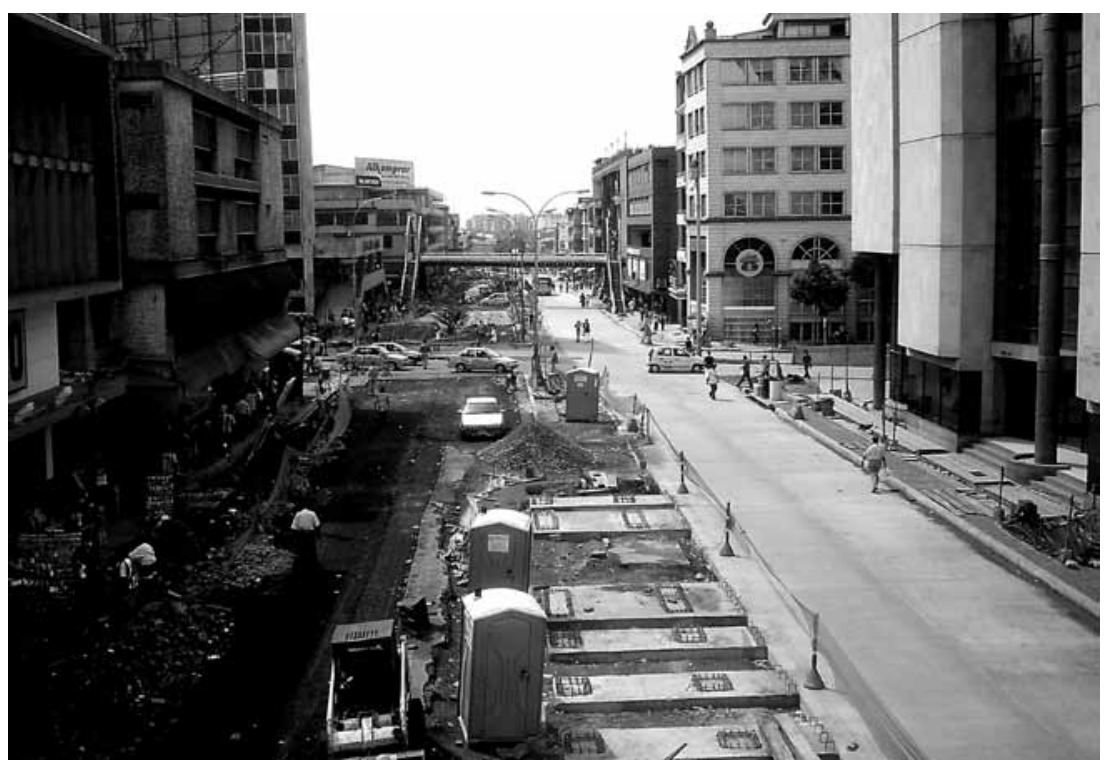

Foto 1. Obras del sistema Metrolínea

Estos efectos negativos del crecimiento urbano son inevitables y la zona central es la primera en sufrirlos. Como resultado, se evidencian procesos de envejecimiento, deterioro y decadencia', marcados por dramáticos cambios en su vocación funcional, se advierte como consecuencia la coexistencia de hacinamiento de actividades con espacios vacíos, desarticulación de la trama urbana y el tejido social, contaminación ambiental y congestión vehicular, que inducen un clima de inseguridad, desarraigo y retroalimenta el proceso de decadencia y expulsa a la población residente hacia la periferia, en busca de una mejor calidad de vida, quedan así, extensas zonas propicias a la marginalidad y al deterioro de los tejidos físico y social. (Foto 2. ) 


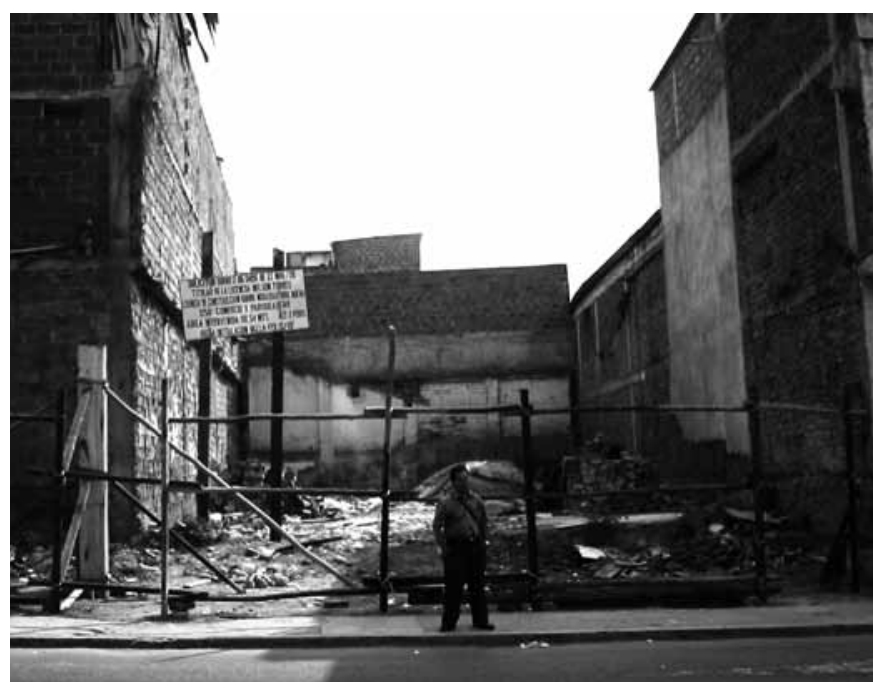

Foto 2. Construcciones en demolición

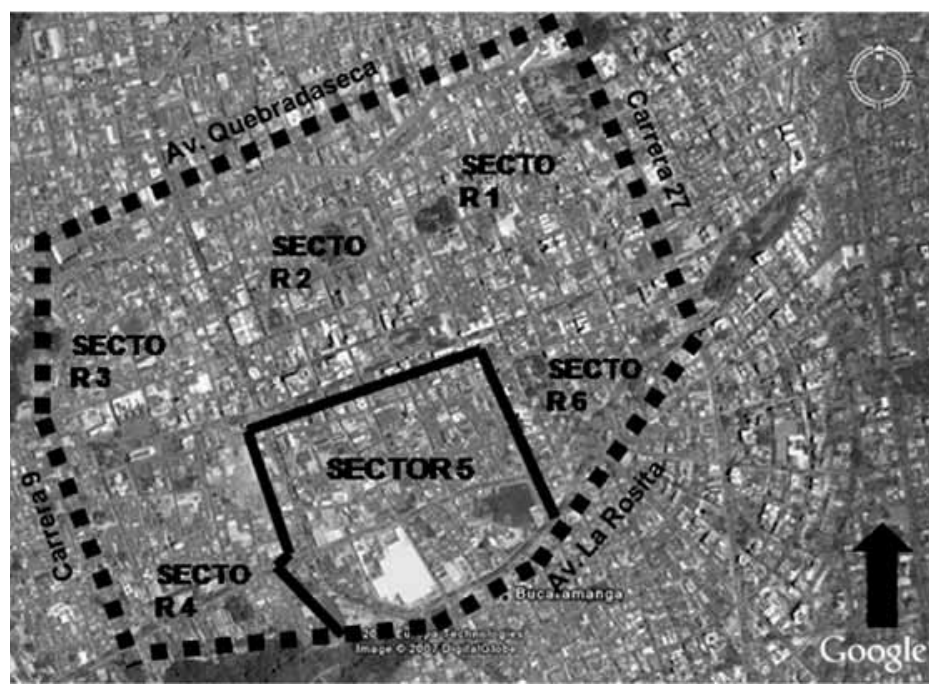

Figura 2. Delimitación del Sector Sectores 1, 2.

El centro de Bucaramanga es el reflejo de graves conflictos urbanos: subutilización y deterioro de grandes áreas y sus infraestructuras, uso ineficiente del suelo, sub-utilización de las estructuras urbanas, multiplicación del número de inmuebles desocupados o en alta degradación arquitectónica, económica y funcional, que propician el desarrollo de actividades informales. Así mismo, esto ha generado la ocupación irracional de los espacios públicos por vendedores ambulantes y estacionarios, locales comerciales y vehículos que se apropian de andenes, calles y parques, que multiplican los focos que degradan el valor inmobiliario y expulsan, tanto la vivienda como la prestación de servicios urbanos. El resultado, una dramática pérdida de calidad de la vida en una de las áreas más representativas de la ciudad.

El sector llegó a un estado tal de degradación, que exige intervenciones urbanísticas y sociales urgentes para la recuperación o cambio de sus relaciones funcionales dentro del contexto de la ciudad. Se requiere una serie de procesos e intervenciones, expresados en su realidad histórica y funcional, en sus potencialidades, en sus tendencias económicas, en la necesidad y oferta de servicios y equipamientos urbanos, en las condiciones propias de movilidad y espacio público, y en la atención a la demanda de vivienda y áreas comerciales. De no actuar con prontitud, la sucesiva evolución natural de los graves conflictos y el constante deterioro de la calidad urbana, hace prever que los actuales problemas se acentúen y que gran parte de las potencialidades y ventajas comparativas que aún presenta el sector se vean diezmadas, e incluso sean irrecuperables. (Figura 2. )

Ante el oscuro panorama del área central de Bucaramanga, y pese al aparente consenso que existe entre dirigentes políticos, el sector privado, la academia, los profesionales dedicados al tema del hábitat, e incluso los sectores sociales más representativos, estamos está en mora para generar un proceso tendiente a la reflexión en torno a la recuperación del sector, y a la generación de propuestas que permitan revertir la cada vez más incontrolable conflictividad de su área central. 


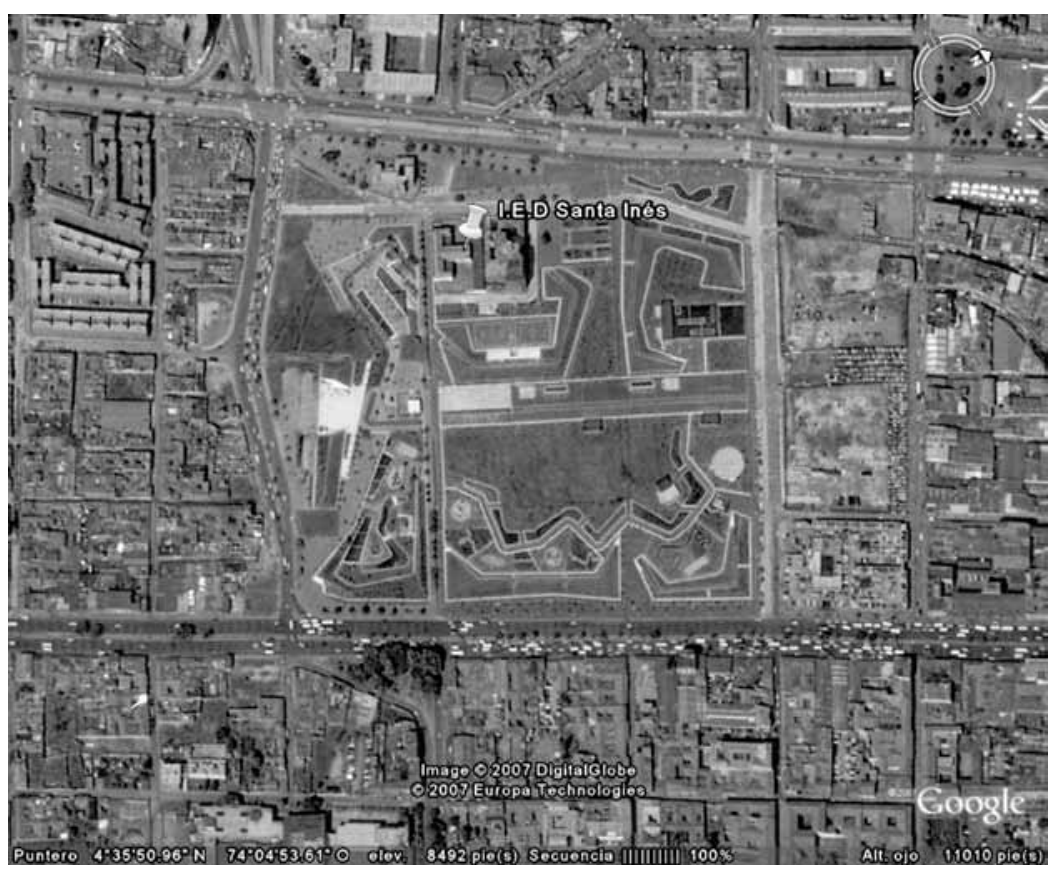

Figura 3. San Victorino

\section{JUSTIFICACIÓN}

El desarrollo de las ciudades se ha convertido en uno de los objetos de análisis más relevantes y frecuentes entre investigadores de diversas instancias. Complejos estudios de movilidad, espacio público, vivienda, o renovación de áreas centrales, desarrollados desde la academia, han originado textos de investigación y reflexión, cartillas, manuales o planes maestros, que han servido de sustento, e incluso han impulsado profundas transformaciones en las principales ciudades del mundo.

En Colombia, Bogotá, Medellín y algunas ciudades del eje cafetero han implementado con relativo éxito planes, programas y proyectos de intervención urbana, surgidos de la iniciativa académica, a partir de ingentes esfuerzos por indagar acerca de las principales causas y efectos de los procesos de urbanización, tanto en el contexto de las ciudades y sus áreas metropolitanas, como a nivel de acotadas porciones de territorio. (Figura 3, 4 y 5 )

En este sentido los más notables ejercicios académicos, muchos de los cuales se han convertido en insumos fundamentales de las políticas nacionales y municipales de planeación del desarrollo urbano, giran en torno a la investigación de s istemas de movilidad urbana, espacio público y renovación de áreas centrales.

Sin embargo, en el contexto local son mínimos los esfuerzos realizados en pro de la investigación de lo urbano y su proyección como fuente de ejercitación práctica que conduzca a la transformación de la ciudad, de sus sistemas estructurantes, o de sectores delimitados de territorio.

Algunos estudios se han realizado a manera de análisis sectoriales de las estrategias y proyectos específicos consignados en el Plan de Ordenamiento Territorial (POT), varios 


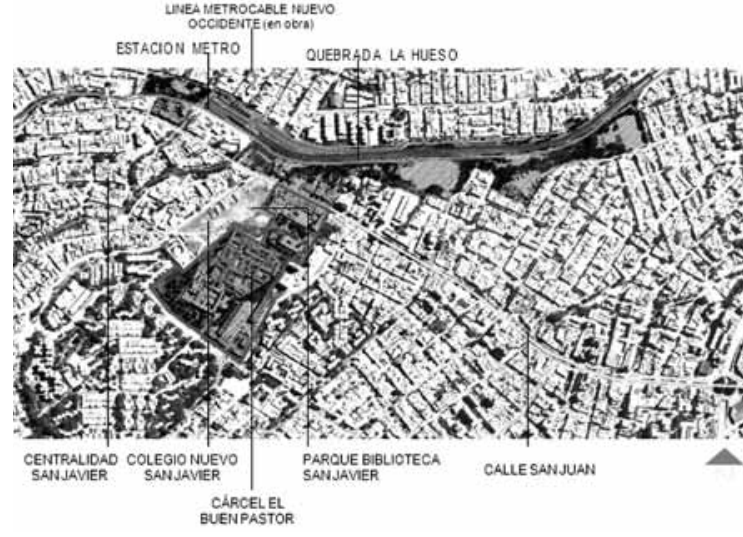

Figura 4. Proyecto la Carcel Medellín

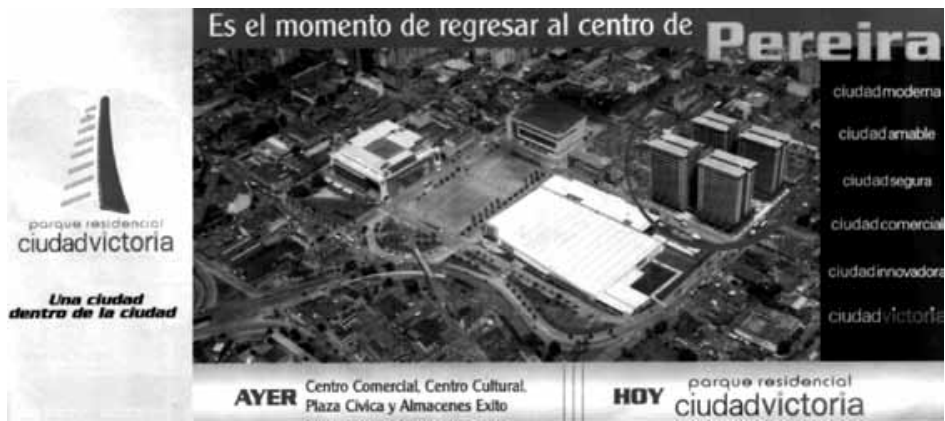

Figura 5. Proyecto Ciudad Victoria - Pereira

desde la perspectiva histórica, a manera de recopilación de antecedentes de desarrollo urbano, otros tantos se han enfocado en la reflexión de la gestión de la ciudad, o en las consecuencias de los proyectos ejecutados. Pero en términos prácticos, son muy escasas las investigaciones que arrojan propuestas territoriales que permitan revalorizar, afianzar o transformar el espacio vital de la ciudad.

Este distanciamiento entre la investigación aplicada y la implementación práctica de Bucaramanga, se ha visto reflejado en la aplicación de políticas sectoriales parciales, que al no contar con ningún tipo de soporte y contrastación desde la academia, terminan por implantarse sin prever las reales consecuencias de su desarrollo, incluso generan un agravamiento de las situaciones que pretendían transformar.

Es tan evidente la falta de iniciativas de investigación sobre los temas de la realidad urbana actual, que desde la aprobación del POT el desarrollo de planes sectoriales sigue siendo una tarea pendiente, que ni el sector público, ni el privado han emprendido, pese a estar reglamentado y ser una norma de obligatorio cumplimiento con miras a alcanzar los objetivos del desarrollo territorial sostenible.

Es precisamente la confluencia de estos dos aspectos: la ausencia de iniciativas y estrategias prácticas de planificación, y la urgente necesidad de generar procesos de renovación en el área central, lo que viabiliza el desarrollo de una propuesta de investigación desde la Facultad de Arquitectura de la Universidad Santo Tomás, que permita no sólo un reconocimiento del área de estudio, sino que también permita la posibilidad de trabajar mancomunadamente con los sectores público y privado, en la implementación de los mecanismos que posibiliten la intervención en el área más significativa de la ciudad.

Hoy más que en otro momento histórico, es un imperativo la formulación de escenarios alternativos que permitan la revisión de las técnicas, procesos y políticas en materia de desarrollo urbano, en especial de las áreas centrales. Es precisamente por este aspecto que la academia no puede permanecer al margen, debe propender por la generación de propuestas que incentiven la participación en el debate alrededor de la consolidación de prácticas de gestión y planeamiento de sectores urbanos altamente conflictivos, a partir de la investigación de las, necesidades y procesos reales del territorio y la sociedad para así poder consolidar que posibiliten la consolidación de modelos de desarrollo que viabilicen su auto sostenibilidad. 
Así mismo, las nuevas corrientes de planeamiento y gestión de las ciudades, han propiciado el desarrollo de investigaciones y metodologías de ordenamiento territorial y planificación ambiental, aplicables a la solución de dichos problemas. En este sentido, las experiencias nacionales e internacionales han demostrado que en medio de crisis agudas se han implementado con éxito instrumentos de desarrollo y gerenciamiento urbano, que facilitan la revitalización de sectores degradados, cuyo resultado final son territorios altamente competitivos, con calidad ambiental y oportunidades sociales.

En el marco de los actuales estudios urbanos, y del énfasis otorgado a su dimensión ambiental, se crea la necesidad de incorporar un espacio desde la academia que permita incorporar la reflexión a las alternativas de recuperación del centro de Bucaramanga.

\section{ESTADO ACTUAL DEL CONOCIMIENTO}

Particularmente en las dos últimas décadas se han realizado, tanto extensos estudios sobre los procesos de revitalización y/o renovación de áreas centrales, como actuaciones prácticas de transformación urbana, a partir de los cambios generados por las nuevas tecnologías de las comunicaciones, la globalización económica, el avance de la información y los sistemas de transporte, que reflejan su directa incidencia en la forma de las ciudades actuales, tratando de contrarrestar la dispersión del tejido urbano en el territorio ${ }^{2}$ y su doble efecto de concentración de actividades en determinados sectores, y en otros, de vaciamiento, especialmente de las áreas centrales.

A partir de los modelos transformadores del París de Haussman y la Barcelona de Cerdá, y de los devastadores efectos reflejados en la segunda postguerra, algunas ciudades europeas iniciaron acciones de intervención en las áreas centrales, mediante proyectos de ordenamiento urbano y renovación, que en las últimas décadas del siglo $\mathrm{XX}$ marcaron el desarrollo de nuevas alternativas para la reelaboración de las prácticas de la planificación territorial. (Figuras 6 y 7 )

Figura 6. Proyecto Barón de Haussman P.

2 Moya, Luis, El proyecto del Espacio Vacío, Publicación de ETSAM - Universidad Politécnica de Madrid, 200I

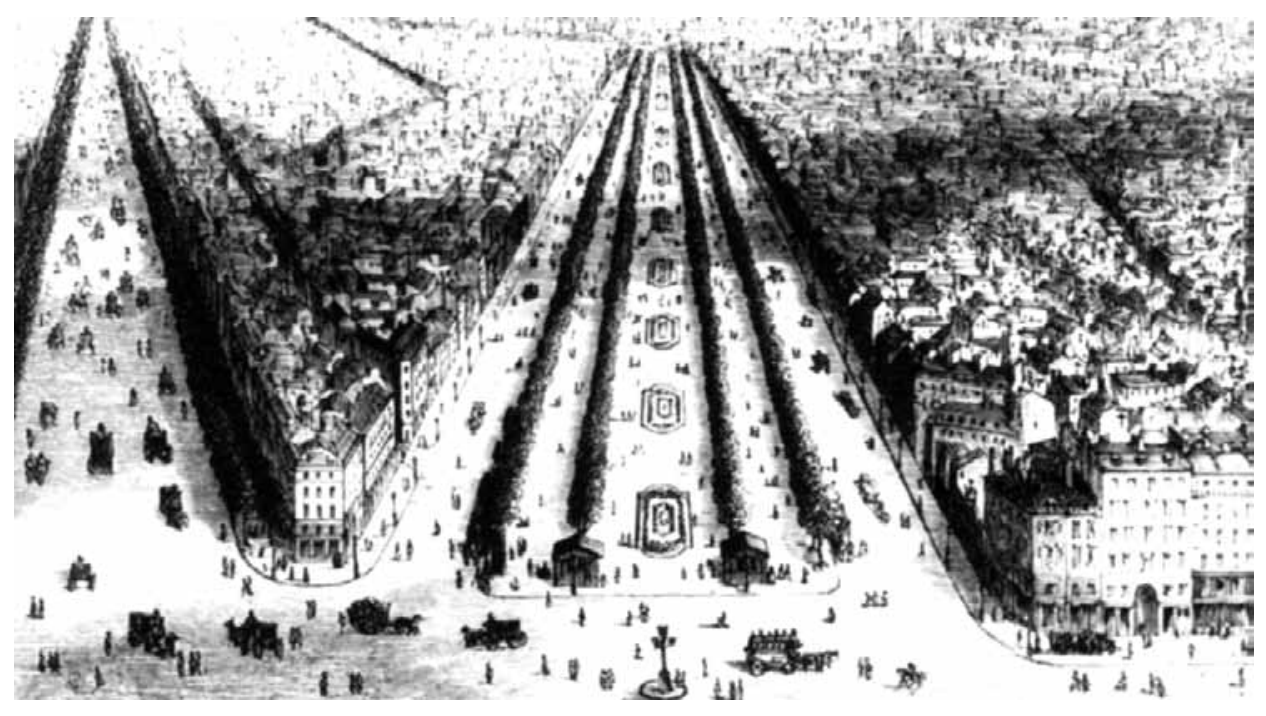


En ciudades españolas como Madrid, Barcelona, Bilbao, Valencia y Sevilla, se dio inicio al desarrollo de importantes operaciones urbanísticas en espacios disfuncionales o en vacíos urbanos de las áreas centrales, que hoy han permitido que dichas ciudades sean más sostenibles y habitables que a comienzos de los años ochenta del siglo anterior.

Este proceso, acompañado de la aparición de nuevas tendencias de desarrollo económico y productivo, generó el surgimiento de un marketing urbano, propiciado por la revalorización de la competitividad entre las ciudades mundiales, y a su vez, dejó en el panorama la necesidad de la modernización y el reordenamiento de las políticas, tanto nacionales como locales en materia de desarrollo urbano.

En medio de este tránsito por nuevas alternativas de intervención urbana, son numerosos los estudios desarrollados que han arrojado como resultado la necesaria tendencia a la revalorización de las herencias patrimoniales, la reorganización funcional, morfológica y social del territorio, así como el fuerte protagonismo de los nuevos usos del espacio urbano relacionados con el turismo, el ocio y la cultura ${ }^{3}$.

Sin embargo, las dificultades encontradas para dar respuesta a la complejidad territorial actual, reflejan uno de los principales escollos del saber y el pensamiento de lo urbano, así como la necesidad de incorporar más instancias de investigación en torno la cultura urbana, en el marco de la comprensión integral de las interdependencias económicas, sociales, políticas que rodean el desarrollo de la sociedad en la ciudad contemporánea.

En los países latinoamericanos la recuperación de las áreas centrales como política de desarrollo urbano es un fenómeno reciente, que se ha posicionado como una de las más fuertes apuestas en favor de la sostenibilidad territorial. Los centros han comenzado a experimentar una revalorización como espacios de calidad para operaciones inmobiliarias y de tercearización, proponiendo alternativas para su aprovechamiento integral, relacionadas principalmente con del desarrollo turístico y cultural.

Figura 7. Ensanche Cerdá, Barcelona.

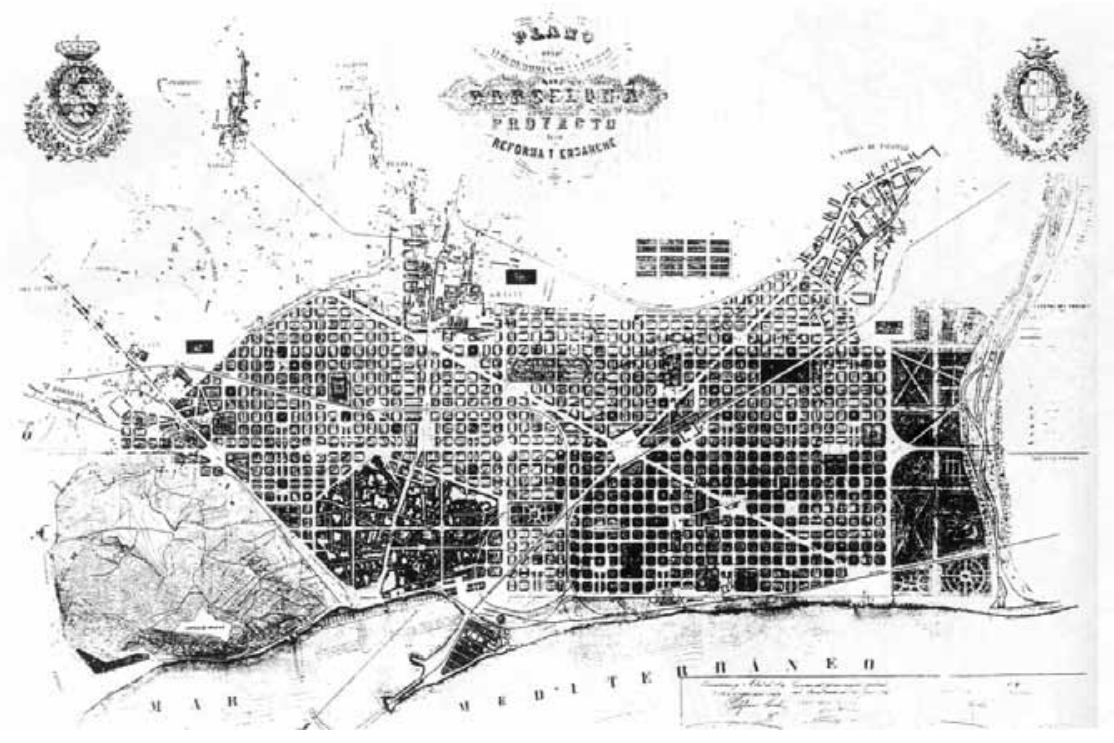

3 Troitiño, Miguel Ángel, artículo renovación urbana: dinámicas y cambios funcionales, universidad politécnica de Cataluña, www.etsav.upc.es, 2003. 
4 MINAMBIENTE, Documentos de renovación urbana, www.minambiente.gov. co, Bogotá, 2004
Estos procesos de transformación han estado precedidos de iniciativas desde la academia por buscar el origen, dar respuestas y plantear alternativas de solución a los dramáticos conflictos aún presentes en las ciudades actuales, que se convierten, en eficaces herramientas que propician la articulación entre el saber académico y la gestión urbanística local.

Así como es intensa la teorización a nivel internacional, en el contexto nacional no ocurre lo mismo. El país carece de experiencia en el análisis de este tipo de operaciones integrales de gran complejidad y escala. Tan sólo a partir de los esfuerzos emprendidos principalmente en Bogotá (sector de San Victorino) Medellín (sector del museo de Antioquia) (Foto 3.) y Pereira (sector de Ciudad Victoria), algunas investigaciones han arrojado interesantes resultados, anticipándose a las intervenciones o como producto de ellas.

El análisis de la acción urbanística colombiana ha permitido un primer nivel de caracterización de la intervención de las áreas centrales, definido por la transformación de la estructura urbana y la reestructuración de su tejido social, bajo un especial sistema de gestión integral por parte de las administraciones locales, que articula acciones en materia social, económica y urbanística.

Así mismo, este despertar tardío a la realidad de los centros urbanos nacionales, ha permitido insertar en la agenda pública el tema de la renovación y conservación de extensas áreas, a tal punto que es ya una política de Estado la transformación de los contextos construidos de las ciudades, demandados por las necesidades del tiempo y la dinámica urbana ${ }^{4}$.

En el marco local, tan sólo un par de propuestas sectoriales formuladas hace más de 20 años, han abordado el tema de la recalificación del centro de Bucaramanga, pero su alcance y propuestas, al perder vigencia y estar formuladas bajo otro contexto socio económico y territorial, es prácticamente desconocido en los estamentos municipales, e incluso entre los sectores académicos.

Hoy los planteamientos cientificistas y las metodologías desarrolladas en los años setenta, y las propuestas formuladas en la década del ochenta, están en mora de ser reemplazadas
Foto 3. Plaza Botero Medellín

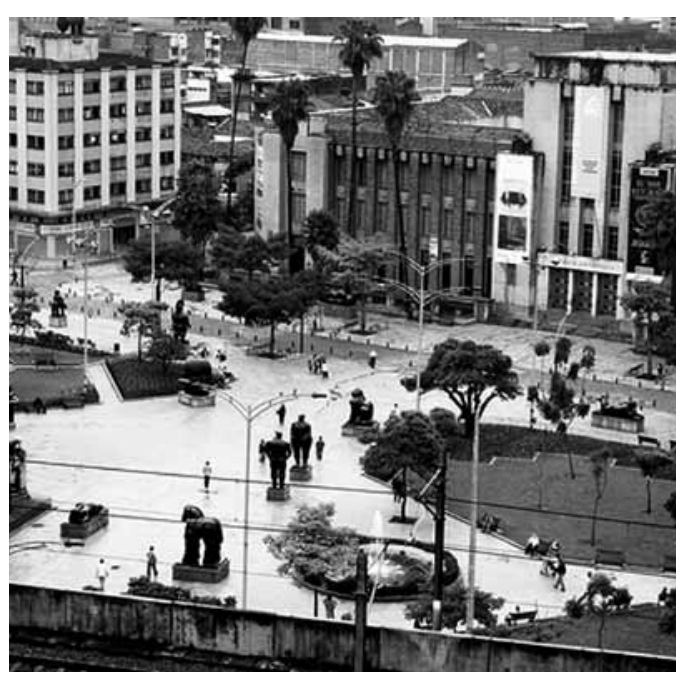

Figura 8. Plano al Código Urbano de Bucaramanga 1972.

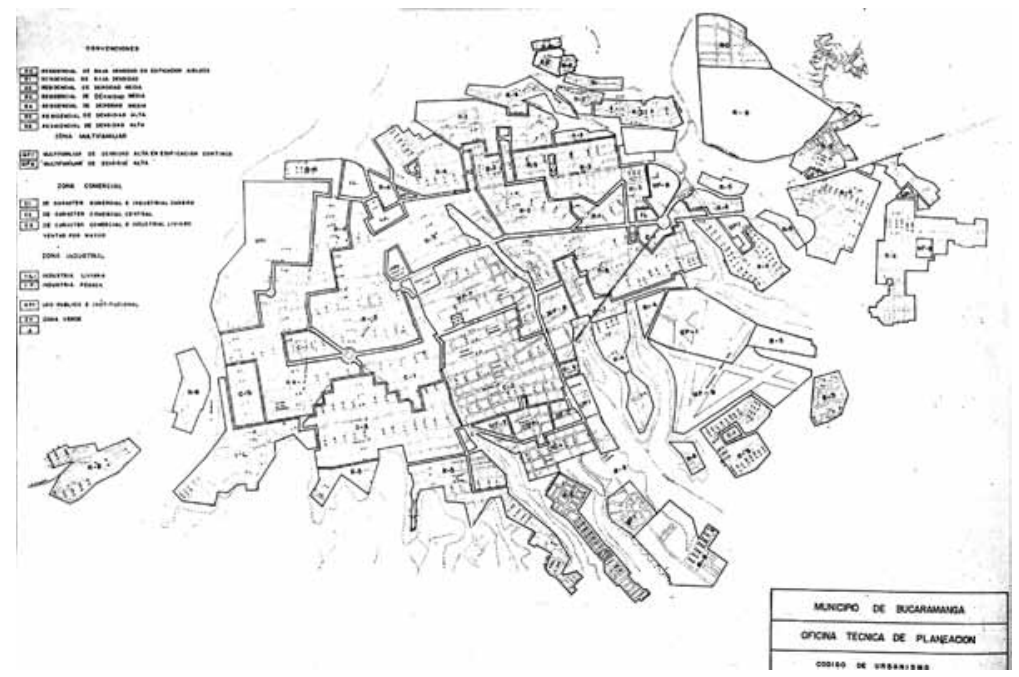


por una visión estratégica del territorio, que permita tanto la proyección de tendencias positivas, como la articulación de modelos de actuación que conduzcan a dar respuestas a la realidad del centro urbano, desde la organización, ocupación y utilización del territorio y su entorno económico, social y político. (Figura 8 )

Aunque la necesidad de generar un proceso integral de recalificación del área central no es un tema nuevo entre los sectores académicos, si lo es en la agenda de las políticas municipales. Así mismo, la ausencia de iniciativas que permitan redireccionar la construcción del conocimiento de la realidad urbana actual, han contribuido al estancamiento de la reflexión en torno a uno de los principales factores de perturbación de la calidad de vida en la ciudad, como es, la degradación del área central.

\section{POLÍTICA NACIONAL URBANA}

El Estado colombiano ha atravesado las vicisitudes propias de una sociedad en construcción, de ello se desprende, que la mayoría de las decisiones sobre el ordenamiento urbano y sus políticas ligadas a la racionalización de los usos del suelo y la implementación de reformas urbanas, han obedecido a los intereses de quienes detentan el poder, no sólo político, sino también y, fundamentalmente el económico.

La lucha frontal por incorporar modelos de desarrollo modernos, entendido como la implementación del derecho como fundamento esencial de una sociedad equitativa, no ha sido fácil. Varios son los intentos por incorporar una normatividad que permita organizar el desarrollo social y económico a la par con un concepto de desarrollo y ordenamiento urbano coherente, como se aprecia en el siguiente cuadro.

\begin{tabular}{|c|c|c|}
\hline PERIODO & PARADIGMA & $\begin{array}{c}\text { INSTRUMENTOS DE ORDENACIÓN } \\
\text { EN EL CASO BUCARAMANGA }\end{array}$ \\
\hline $\begin{array}{l}\text { PRIMER PERIODO } \\
1950-1970\end{array}$ & $\begin{array}{c}\text { SOCIEDAD MODERNA } \\
\text { Y EL ESTADO DE } \\
\text { BIENESTAR }\end{array}$ & $\begin{array}{l}\text { CÓDIGOS URBANOS I945, } \\
\text { I } 966 \text { INFLUENCIAS DEL } \\
\text { CIAM PLANOS REGULADO- } \\
\text { RES LEYES DE LA REPÚBLICA } \\
\text { POLÍTICAS ICT INTENTOS DE } \\
\text { REFORMAS URBANAS }\end{array}$ \\
\hline $\begin{array}{l}\text { SEGUNDO PERIODO } \\
\text { PRINCIPIOS DE LOS } \\
70 \text { a PRINCIPIOS } \\
\text { DE LOS } 90\end{array}$ & $\begin{array}{l}\text { PLANIFICACIÓN } \\
\text { INTEGRAL }\end{array}$ & $\begin{array}{l}\text { CÓDIGOS URBANOS } 1972,1982 \\
\text { LEYES DE LA REPÚBLICA POLITICAS } \\
\text { ICT EINURBE REFORMAS URBANAS }\end{array}$ \\
\hline $\begin{array}{c}\text { TERCER PERIODO: } 90 \\
\text { HASTA LA } \\
\text { ACTUALIDAD }\end{array}$ & $\begin{array}{l}\text { CIUDAD DESREGULADA A } \\
\text { LA CIUDAD GLOBAL }\end{array}$ & $\begin{array}{l}\text { CÓDIGOS URBANOS I } 982 \text { PLANES } \\
\text { DE ORDENAMIENTO TERRITO- } \\
\text { RIAL POT LEYES DE LA REPÚBLICA } \\
\text { POLITICAS ICTE INURBE REFORMAS } \\
\text { URBANAS }\end{array}$ \\
\hline
\end{tabular}

Cuadro 1. Periodización y paradigmas del planeamiento en Colombia.

Fuente: Ciudades y Ciudadanía la política del santo social

Durante el primer periodo se destaca el acontecimiento infortunado del "Bogotazo", como un episodio que marcó las reformas urbanas en Colombia. Una reforma que fue presionada por dos factores, de una parte el nivel de destrucción de un sector importante del centro de Bogotá, y de otra, los intereses de los dueños de la tierra, que animados por la visita de 
$5 \quad$ VALENCIA, Jaramillo Jorge. Isaza Giraldo Fabio (editor) Las Reformas urbanas en Colombia. En: Reforma Urbana y Desarrollo Social. Ed. CAMACOL, 1989
Lecorbusier a Colombia, vieron el acontecimiento como inmejorable para llevar a cabo un proyecto Moderno en Colombia. De hecho la mayoría de los códigos urbanos tienen su origen en las influencias aportadas por los visionarios extranjeros que llegaron a Bogotá, entre ellos y con una anterioridad importante Kar Bruner, y posteriores a LeCorbusier, Sert y Wiener, entre otros. (Figura 9)

Las propuestas de reforma urbana de este periodo se quedaron todas en el papel, como lo destaca Jorge Valencia Jaramillo. "en Colombia no se ha podido llevar a cabo una reforma urbana. Tampoco se ha podido aprobar una Ley sobre el particular porque en el país hay leyes - bastantes - que ordenan muchas cosas que no se hacen, o se hacen a medias o se hacen mal." 5

Durante el segundo periodo, se impone en Colombia el planeamiento promovido por la CEPAL y por el Plan de las Cuatro Estrategias propuesto por el presidente Pastrana, el plan planteaba en su primera estrategia el problema urbano, de cuya propuesta surgen la aplicación del proyecto de "Ciudades dentro de la ciudad", el propósito era, de una parte, convertir a la construcción en una industria, y de otra, frenar la expansión urbana a partir de proyectos centrales. En el caso particular de Bucaramanga dicha propuesta se materializó en el proyecto Ciudadela Real de Minas.(Figura 10)

El periodo es testigo del fortalecimiento de las CAV y de las empresas constructoras, en detrimento de la política del Estado para el desarrollo urbano. El sistema de crédito privado se fortaleció y la producción de vivienda por parte del Estado cayó vertiginosamente hasta desaparecer. A su vez, los sectores céntricos de casi todas las ciudades colombianas entraron en franco detrimento, las migraciones presionadas por múltiples factores, encontraron en el espacio público su mejor escenario.

El tercer periodo coincide con los procesos políticos violentos que concluyeron con la reformulación de la carta magna, la constitución política de 1991. El suceso no es de poca monta, es allí, en el Congreso, en donde se empieza a gestar una profunda reforma a la
Figura 9. Plan LeCorbusier para Bogotá

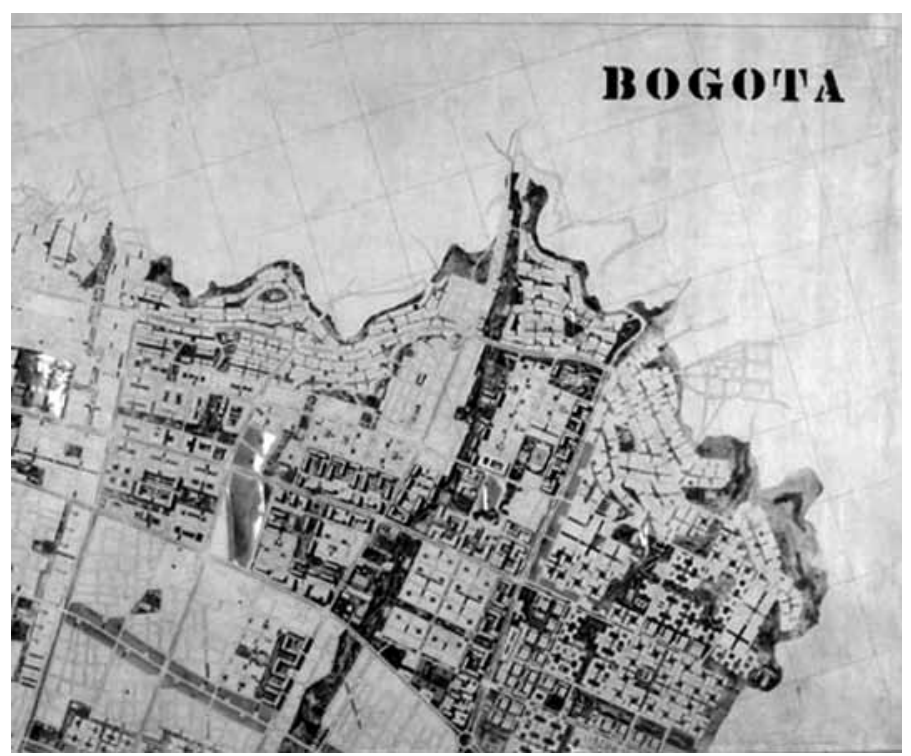

Figura 10. Proyecto Ciudadela Real de Minas de Bucaramanga

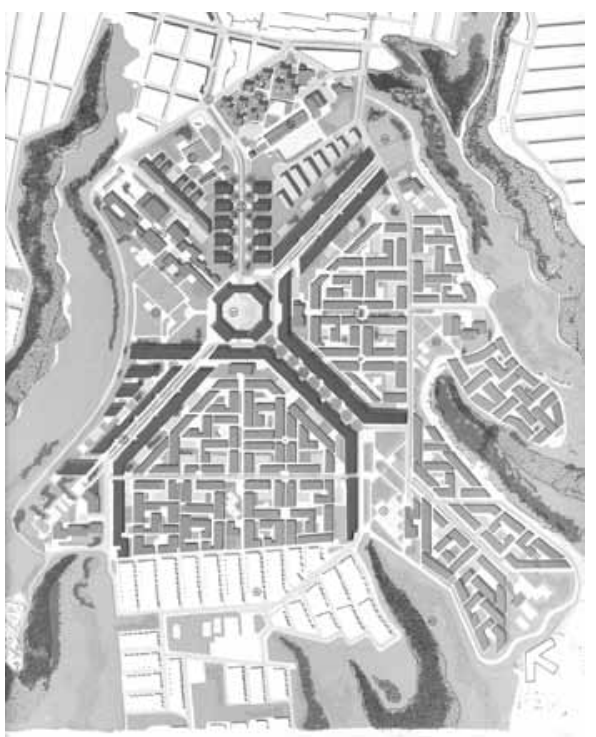




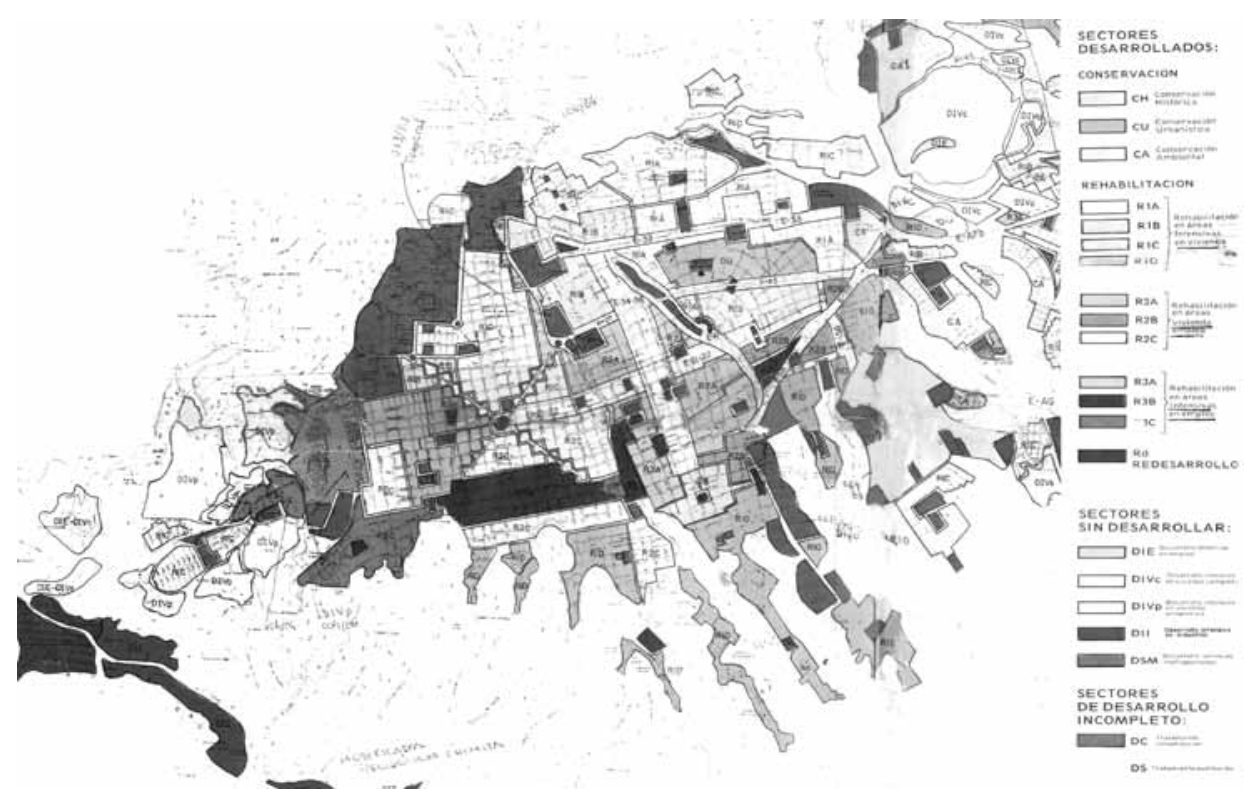

Figura 11. Código Urbano, 1982

participación ciudadana, frente a los problemas más complejos de su realidad, económica, social, cultural y política. La fundación de un nuevo concepto de Estado social de derecho, implementa nuevas visiones del planeamiento y el derecho a la ciudad. Un territorio y una ciudad escindida que requiere ahora más que nunca, de empoderamiento social y mayores niveles de coparticipación y corresponsabilidad en todos sus ámbitos.

Ley 388, es el corolario de las profundas e históricas discusiones sobre el planeamiento urbano y territorial en Colombia, sentó sus principios fundamentales en:

- La función social y ecológica de la propiedad.

- La prevalecía del interés general sobre el particular.

- La distribución equitativa de cargas y beneficios del urbanismo.

- La función pública del urbanismo.

- La participación democrática de los individuos.

Se buscaba así armonizar la Ley 9 de 1989 con la Constitución y las Leyes 3 de 1991 (Sistema Nacional de VIS), 99 de 1993 (Sistema Nacional Ambiental), 128 de 1994 (Áreas Metropolitanas), 152 de 1994 (Ley Orgánica de Planificación) y fortalecer el proceso de descentralización al cual le apostaba el país. Entre sus principales instrumentos, la Ley trajo la figura del Plan de Ordenamiento Territorial, herramienta fundamental para la organización física de los municipios y distritos del país, así como del archipiélago de San Andrés y Providencia, y a través de la cual se implementarían una serie de instrumentos de planeación, de gestión y de financiación tendientes a cumplir dicho objetivo, tales como los planes parciales, las unidades de actuación urbanística, el reparto equitativo de cargas y beneficios y la expropiación, entre otros. (Fig. II) 


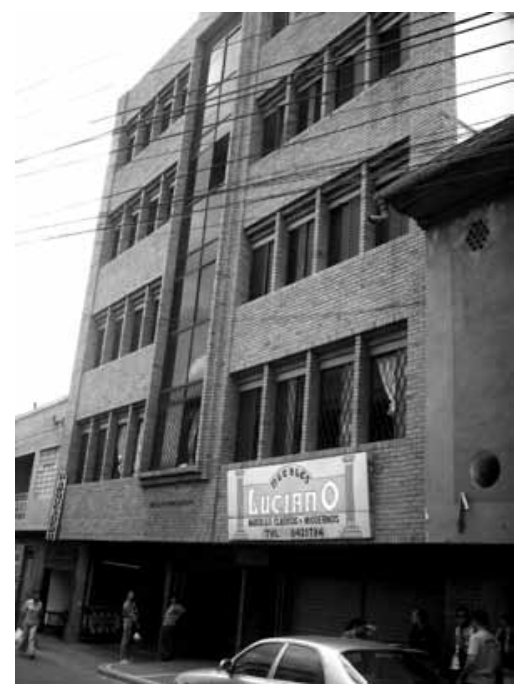

Foto 4. Densificación del Sector

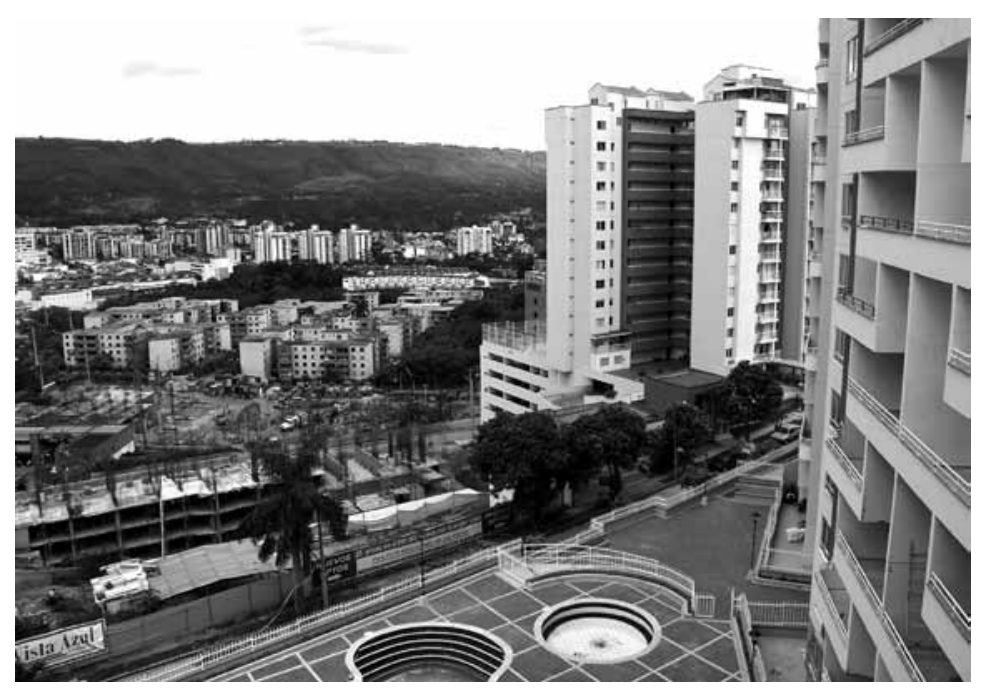

Foto 5. Aspecto de las Urbanizaciones Cañaveral
6 GOUESET, Vincent. BOGOTÁ NACIMIENTO DE UNA METROPOLI la originalidad de crecimiento urbano en Colombia. Ed. Tercer Mundo Editores, observatorio de cultura urbana, CENAC, IFEA y FEDEVIVIENDA, Bogotá 1998

7 DANGOND Gibsone Claudia, JOLLY Jean-Franaois, MONTEOLIVA Alejandra, NIÑO Soto Alexánder. UNA REFLEXIÓN CRÍTICA SOBRE LOS LINEAMIENTOS DEL DOCUMENTO CONPES 3305. En: Pap. Polit. Bogotá (Colombia), Vol. II, No. I, 47-68, enerojunio 2006, ISSN 0122-4409
A su turno el CONPES 3305, hace un análisis de la situación urbana del país en donde define las características económicas y productivas del sistema de ciudades en Colombia, plantea que las 7 ciudades principales generan alrededor del $65 \%$ del PIB y concentran el $45 \%$ de la población urbana nacional, donde la capital, Bogotá', concentra el $22 \%$ del PIB y el $21 \%$ de la población urbana. En el mismo sentido Goueset ${ }^{6}$ propone que Colombia enfrenta un fenómeno que va de la cuadricefalia urbana, a una macrocefalia, es decir, a una tendencia en donde la capital del país tiende a concentrar la mayoría de la población y la riqueza.

La marcada tendencia a la tercerización de la economía se identifica en el documento. Se reconoce que la mayoría del PIB urbano es generado por actividad de servicios, propiciando un mayor desequilibrio de las estructuras urbanas de las ciudades colombianas, en las cuales antiguas zonas de vivienda fueron incorporadas para el uso comercial y de oficinas, sin los debidos procesos de adaptación, junto con el deterioro y la progresiva obsolescencia de las zonas industriales. ${ }^{7}$

El documento recoge los elementos sustanciales de una estrategia de renovación urbana, apuntan y a la solución de los problemas del "agotamiento" de los suelos urbanizables. Se centra en asuntos como el deterioro urbano y sus posibilidades de renovación, en donde la ciudad compacta, en contraposición a la ciudad dispersa resultarían ser las ideales. Así mismo plantea los problemas que tienen los procesos cada vez más marcados de la renovación predio a pedio, sin planeamiento y responsables de una densificación sin criterio en donde las infraestructuras no soportan dichas cargas. (Foto 4)

Tres son los elementos claves de la política del Estado contenidos en el documento "Estrategia de ciudades amables": saneamiento para asentamientos: mejoramiento integral de barrios SPA:MIB, macroproyectos para vivienda para vivienda de interés social, renovación y/o redencificación urbana, así mismo se incluyen la vivienda, el saneamiento básico y el sistema de movilidad. Para el logro de dichas metas, se proponen los siguientes objetivos:

- Optimizar la conectividad y movilidad urbana

- Fortalecer la planificación local y regional para optimizar la localización de actividades y equipamientos

- Mejorar la calidad de vida de las ciudades: 
- Aumentar las coberturas de servicios públicos y el acceso a la vivienda.

- Conservar y promocionar el patrimonio cultural e histórico.

- Incrementar la calidad y cantidad de espacio público.

- Promover ambientes urbanos seguros y accesibles para toda la población.

- Fortalecer las políticas de cultura ciudadana. ${ }^{8}$

En síntesis, una política de Estado para "recomponer "los desajustes producidos hasta el presente. Se parte en principio de que se "fortalecerá la utilización de la fiducia mercantil y la expropiación administrativa a terceros y demás instrumentos que permitan un mayor desarrollo de actuaciones urbanísticas integrales de renovación y/o redensificación."

\section{Corrientes actuales}

Las corrientes del planeamiento actual, permiten afrontar la cuestión urbana, abogando por una nueva cultura de la ciudad y del territorio, mediante la adaptación de la ciudad tradicional a las nuevas necesidades desde el ámbito de la gestión y el planeamiento de estrategias integrales de recuperación, que ajusten los ritmos de los procesos económicos, sociales, políticos y urbanísticos, superando la planeación netamente arquitectónica, dando cabida a funciones emergentes como la turística y la cultural.

Es así como el marco de la planificación de los procesos territoriales se centran en la búsqueda de las conexiones entre las políticas de recuperación urbana y la planificación estratégica, es decir, pensar la ciudad en forma estratégica y global, visión que implica tanto insertarla en el territorio como identificar las claves funcionales de su dinámica interna ${ }^{10}$.

Esta forma de abordaje de la planificación territorial, ha permitido la caracterización de los procesos urbanos: la aceleración de los ritmos de crecimiento espacial de las ciudades, el desarrollo de nuevas formas de ocupación territorial, los conjuntos cerrados, los subcentros periféricos, entre otros, dejan como consecuencia un vaciamiento de las áreas centrales, lo que plantea múltiples interrogantes sobre la sostenibilidad de estas formas de organización del espacio urbano. (Foto 5)

Conservación frente a renovación, concentración frente a dispersión, multifuncionalidad frente a especialización, segregación frente a integración, son los retos que imponen las actuales formas del planeamiento territorial. En este sentido, las más recientes corrientes de planeamiento y gestión de las ciudades, están apostando por procesos de reorganización a dos velocidades: por un lado, acelerada en los espacios centrales, y por el otro, lenta en los espacios periféricos.

Sea cual sea el modelo a implementar, lo que se busca es la reorganización del espacio interno de la ciudad, a nivel funcional, social y morfológico, para así terminar de desarrollar la ciudad existente, a partir de la recalificación de las áreas centrales. Esto implica la recuperación de la ciudad heredada, por medio de estrategias desde la funcionalidad en relación con la reutilización productiva de las áreas de ocio, la cultura, el turismo y la residencia principalmente.

La recualificación de la zona central implica el análisis enfocado en la interdependencia entre las dinámicas urbanas y los procesos territoriales del centro como conjunto que ofrece las bases de una singularidad reconocible, identificable, como un punto de convergencia y espacio de concentración, que le confiere el valor de núcleo".
8 BAYONA Chaparro José Alejandro, Foro: Por una Colombia Bien Gobernada 2008 - 20 I I Santa Marta, 15 de Abril de 2008

9 Ibíd. 
12 Mesías González, Rosendo y Suárez Paredón Alejandro, Los Centros Vivos, Centro de Vivienda y Estudios Urbanos, Lima, 1997
A su vez, plantea el establecimiento de conexiones más estrechas entre las políticas de recuperación urbana y el planeamiento estratégico, para encontrar nuevos equilibrios entre las realidades físicas, económicas y sociales, que impulsen la producción social del hábitat ${ }^{\prime 2}$, integrando esfuerzos y responsabilidades de los residentes, con las instancias institucionales públicas y privadas.

De esta forma, el punto de partida para abordar la propuesta de recuperación urbana del área central de Bucaramanga, consiste en reconocer al territorio y la ciudad, como fenómenos de alta complejidad, en los que los procesos de gestión y planeamiento son sensibles a las lógicas particulares de su conformación económica, social, política, urbana, ambiental e histórica. (Foto 6)

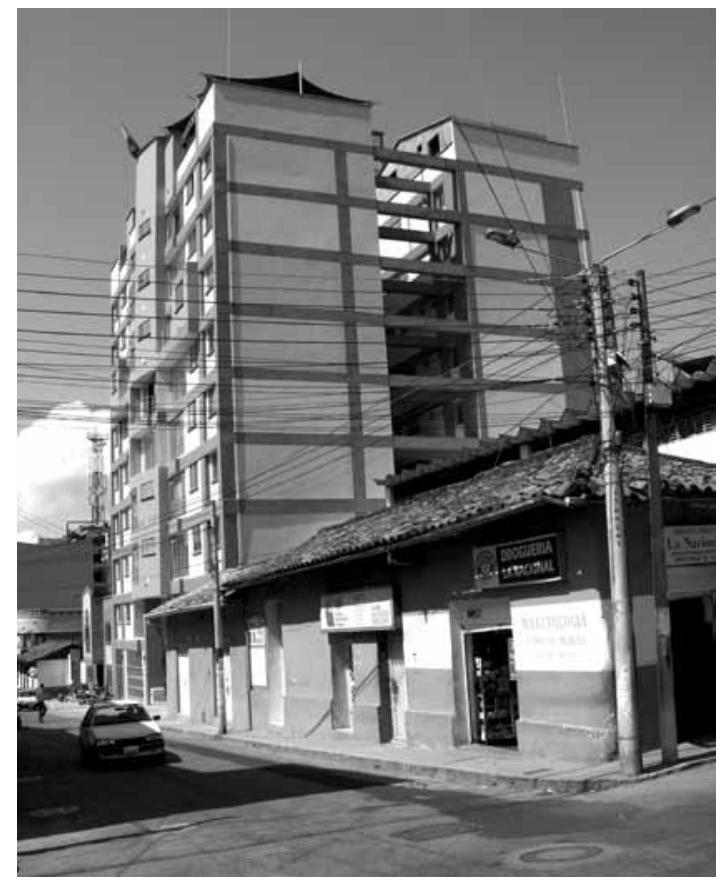

Foto 6. Redensificaciones por sustitución

\section{HIPÓTESIS}

El desconocimiento de las dinámicas de transformación urbana del área descrita, imposibilita el desarrollo coherente y la implementación de un modelo sostenible de desarrollo urbano.

\section{Hipótesis Específicas}

- Los efectos negativos del crecimiento urbano y la confluencia de múltiples actividades en el área central de Bucaramanga, tienen como consecuencia la conformación de un sector degradado que no es capaz de responder satisfactoriamente a las actuales demandas territoriales.

- La inserción de nuevos capitales representados en dotaciones y equipamientos públicos o privados de amplio espectro generan nuevas posibilidades de recualificación urbana. El evento de la localización del almacén Éxito sobre la diagonal I 5 con Avenida la Rosita, evidencia la anterior proposición. 
- La problemática actual del centro es una manifestación del cambio en su vocación funcional original y de los desequilibrios en el espacio interno, marcado por la aparición de zonas susceptibles a la marginalidad y al deterioro de los tejidos físicos y sociales.

\section{OBJETIVO GENERAL DEL PROYECTO}

Estudiar las transformaciones urbanas del área central de Bucaramanga.

\section{OBJETIVOS ESPECÍFICOS}

- Realizar un minucioso levantamiento urbano del área acotada.

- Implementar herramientas técnicas del planeamiento sobre procedimientos específicos de recolección, caracterización, procesamiento y evaluación de información primaria y secundaria.

- Desarrollar mecanismos de contrastación práctica entre los usos teóricos planteados y su materialización.

- Incorporar criterios conceptuales, instrumentales y metodológicos para la coherente formulación de instrumentos de gestión y el planeamiento del área central.

- Formular un modelo metodológico que pueda replicarse para la investigación de fenómenos urbanos específicos.

- Producir un estudio académico que sustente la recalificación del área central y abra la posibilidad de articular iniciativas de desarrollo con las instancias institucionales locales.

\section{MATERIALES Y MÉTODOS}

\section{Métodos, procedimientos y actividades}

En principio, el diseño metodológico estuvo condicionado por la limitación propia de los estudios académicos, referida principalmente al grado de participación social necesaria, a la recolección y elaboración de información detallada y precisa que refleje fielmente la realidad del área central, lo que requeriría la disposición de una cantidad considerable de recursos técnicos, físicos, económicos y humanos.

Para el desarrollo de las etapas propuestas en la metodología general y en especial de la fase preliminar, se organizaron los procedimientos y las actividades básicas necesarias para iniciar el proyecto, mediante la revisión y complemento del planteamiento metodológico: (Figura 12)

- Ajuste del trabajo desde las asignaturas electivas:

- Revisión, discusión y complemento de los contenidos temáticos de las asignaturas de apoyo de la investigación, mediante la estructuración de temáticas, instancias y procedimientos particulares. 
- Estructuración de un grupo de estudiantes de base:

- Definición de objetivos y alcances del trabajo con los alumnos.

- Convocatoria estudiantil para el apoyo a la investigación, con el fin de conformar un grupo de base independiente de los tiempos académicos de las asignaturas electivas.

- Selección de un grupo de cuatro estudiantes como equipo base.

- Difusión y capacitación:

- Presentación del proyecto de investigación al grupo de trabajo (alumnos regulares de las asignaturas electivas y alumnos seleccionados en la convocatoria).

- Capacitación sobre técnicas generales y específicas de recolección de información.

- Trabajo de campo inicial: recorridos urbanos y caracterización del sector.

- Aproximación a la situación física del área a estudiar, reconocimiento y caracterización del sector en el contexto municipal y de su incidencia en la estructura física y funcional de la ciudad.

- Elaboración de formatos para la recolección de información.

- Información urbana general.

- Información predial general.

- Cuestionarios.

- Consecución, análisis y re elaboración de cartografía básica

Figura 12. Planillas de Recolección de Información
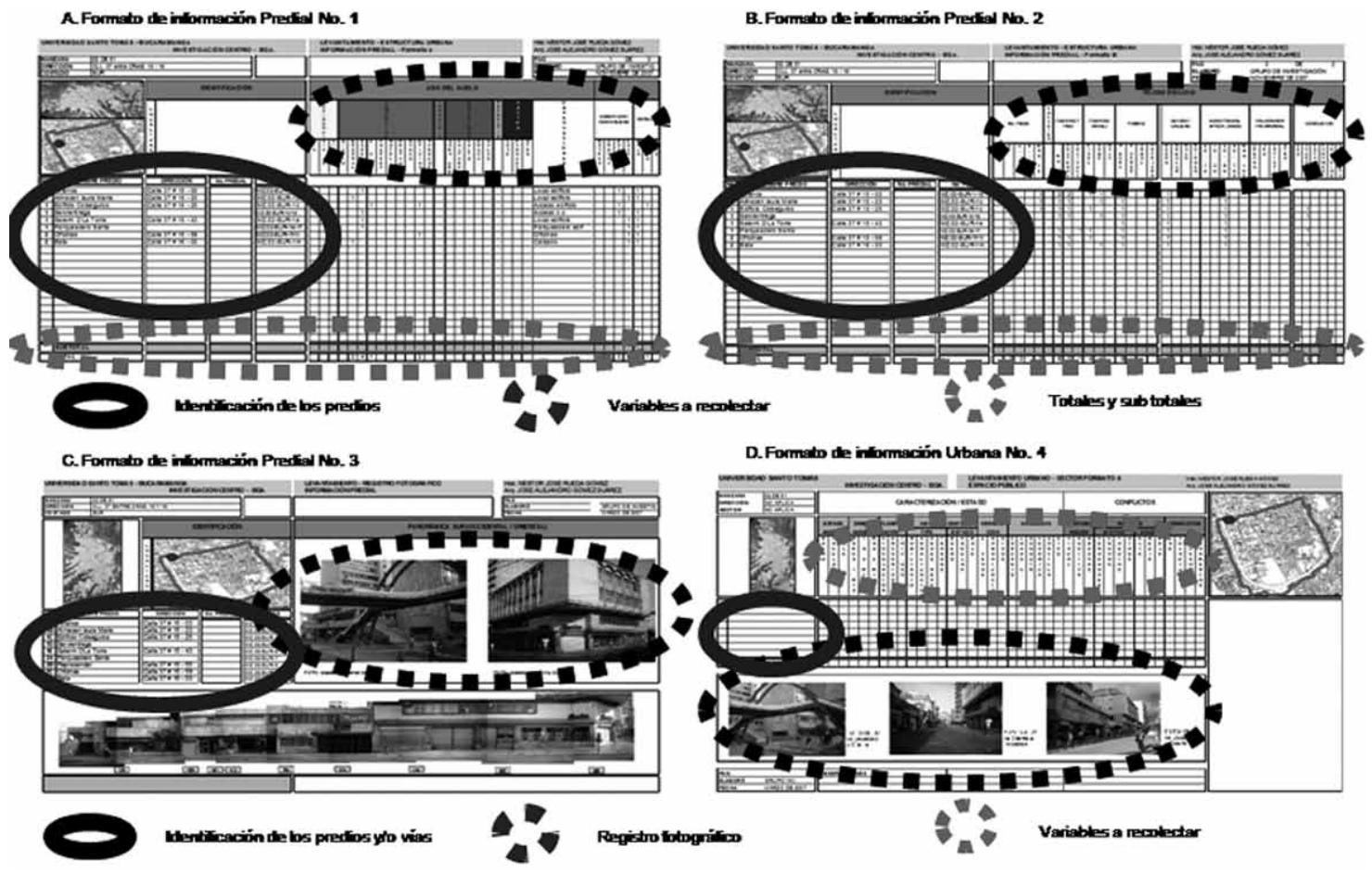

D. Formato de intormaciön Utbana Nb. 4

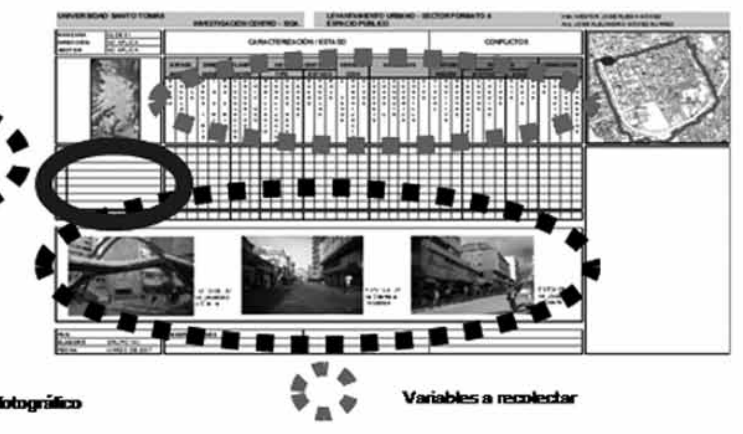




\section{RESULTADOS}

\section{VARIABLES: (I) Sistema natural, Configuración histórica, Forma y tamaño de manzanas}

Al realizar un análisis comparativo y una superposición de las anteriores variables particu lares, es posible realizar la siguiente caracterización territorial.

\section{Descripción / Explicación}

Hacia el sur, en el sector de la Avenida la Rosita, se presenta un trazado urbano configurado por manzanas de gran tamaño, algunas de las cuales presentan formas irregulares, debido principalmente a las características geográficas y topográficas del sector (antigua quebrada la Rosita, actualmente rellena y canalizada).

La configuración de los caminos históricamente trazados en el sector, han definido un trazado urbano irregular. (Foto 7 )

\section{Evaluación / Proyección}

El relleno de la quebrada la Rosita, ha generado una morfología urbana compleja y una restricción técnica para el desarrollo de proyectos de gran altura, que complementen los usos comerciales característicos del sector. (Foto 8.)

\section{VARIABLES: (2) Forma y tamaño de manzanas, Tamaño de predios, Conectividad vial}

Al realizar un análisis comparativo y una superposición de las anteriores variables particulares, es posible realizar la siguiente caracterización territorial.

Foto 7. Panorámica Bucaramanga años 20.

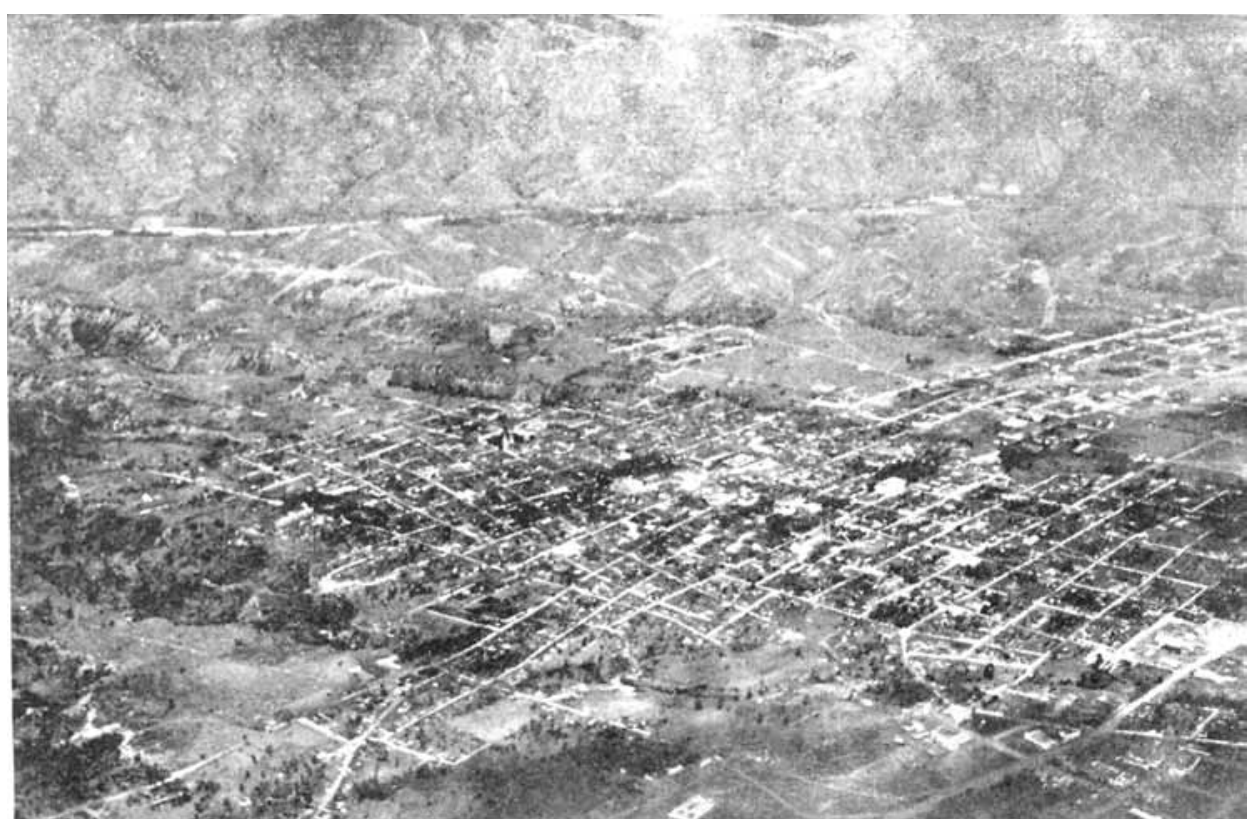




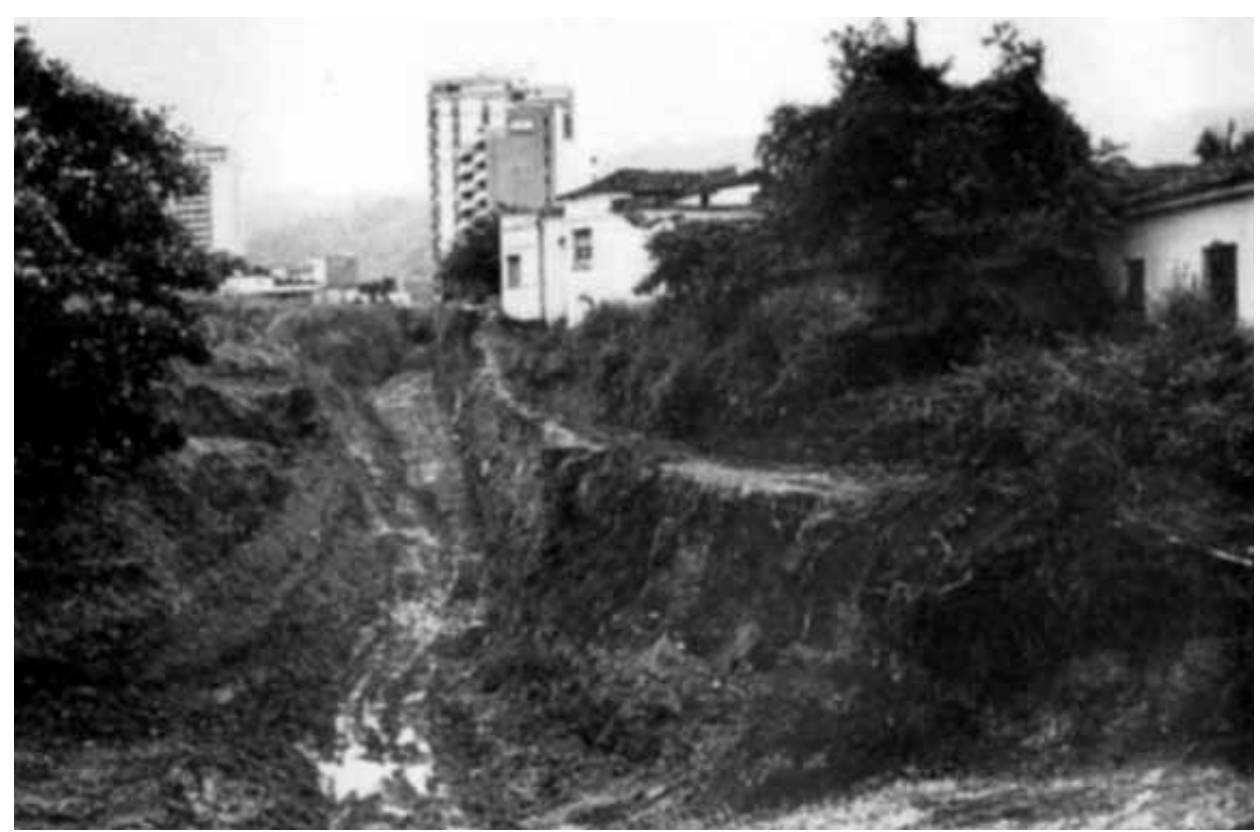

Foto 8. Quebrada La Rosita

\section{Descripción / Explicación}

Hacia el sur, en el sector de la Avenida la Rosita, se presenta un trazado urbano configurado por manzanas de gran tamaño, que a su vez está conformada por predios de gran tamaño, ubicados hacia la vía más importante del área sur (Av. La Rosita).

Los predios de tamaño mediano se ubican principalmente hacia el costado norte y occidental, a lo largo de los ejes viales de la carrera 15 y la calle 37.

\section{Evaluación / Proyección}

Los predios de tamaño superior se ubican hacia la zona sur, y los de tamaño mediano hacia los sectores norte y occidental, a lo largo de los principales ejes viales, con lo que hacia el interior se desarrollan los predios de tamaño pequeño, generando un aislamiento de dicha zona, y en algunos casos una sobre utilización del suelo

\section{VARIABLES: (3) Usos del suelo, Conectividad vial, Uso comercial}

Al realizar un análisis comparativo y una superposición de las anteriores variables particulares, es posible realizar la siguiente caracterización territorial.

\section{Descripción / Explicación}

Las áreas comerciales se han desarrollado a lo largo de los principales ejes vehiculares (carrera 15, Av. La Rosita, calle 45, y calle 37), debido tanto a la configuración de los caminos históricamente trazados en el sector, como a la búsqueda de los sectores de mayor actividad urbana. 


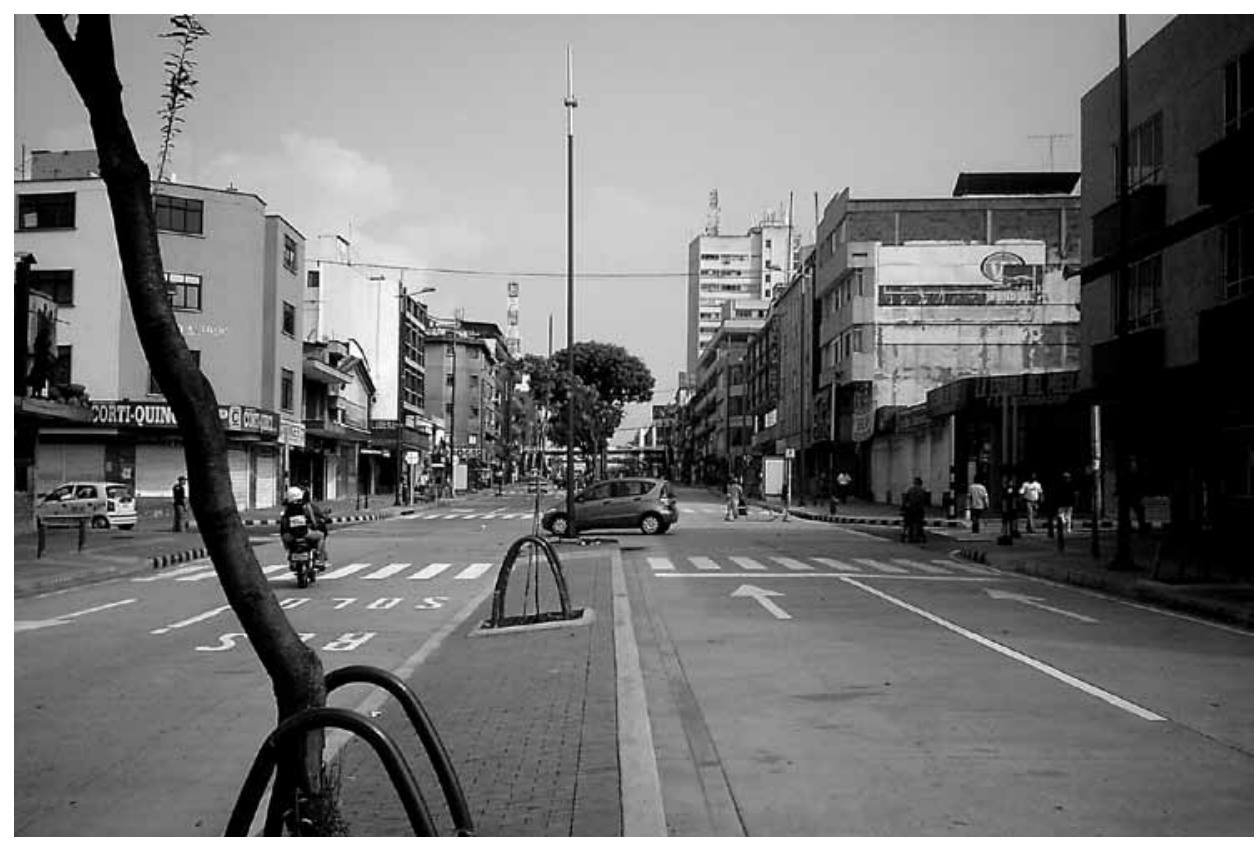

Foto 9. Panorámica carrera 15

El eje de la carrera 15 se convierte en el principal articulador de la actividad comercial debido al gran desarrollo viario y a su conexión directa con otros sectores de la ciudad. (Foto 9)

\section{Evaluación / Proyección}

La estructuración de los 4 ejes comerciales ha generado un desarrollo dispar en el sector, dejando áreas como la central, relegada para el establecimiento de actividades urbanas de condiciones deficientes.

\section{VARIABLES: (4) Usos del suelo, Conectividad vial, Dimensión de vías}

Al realizar un análisis comparativo y una superposición de las anteriores variables particulares, es posible realizar la siguiente caracterización territorial.

\section{Descripción / Explicación}

Aunque el sector es predominantemente comercial, a lo largo de los principales ejes vehiculares (carrera 15, Av. La Rosita y la calle 45), se desarrolla la mayor actividad comercial.

El eje de la carrera 15 se convierte en el principal articulador de la actividad comercial debido al gran desarrollo viario y a su conexión directa con otros sectores de la ciudad. 


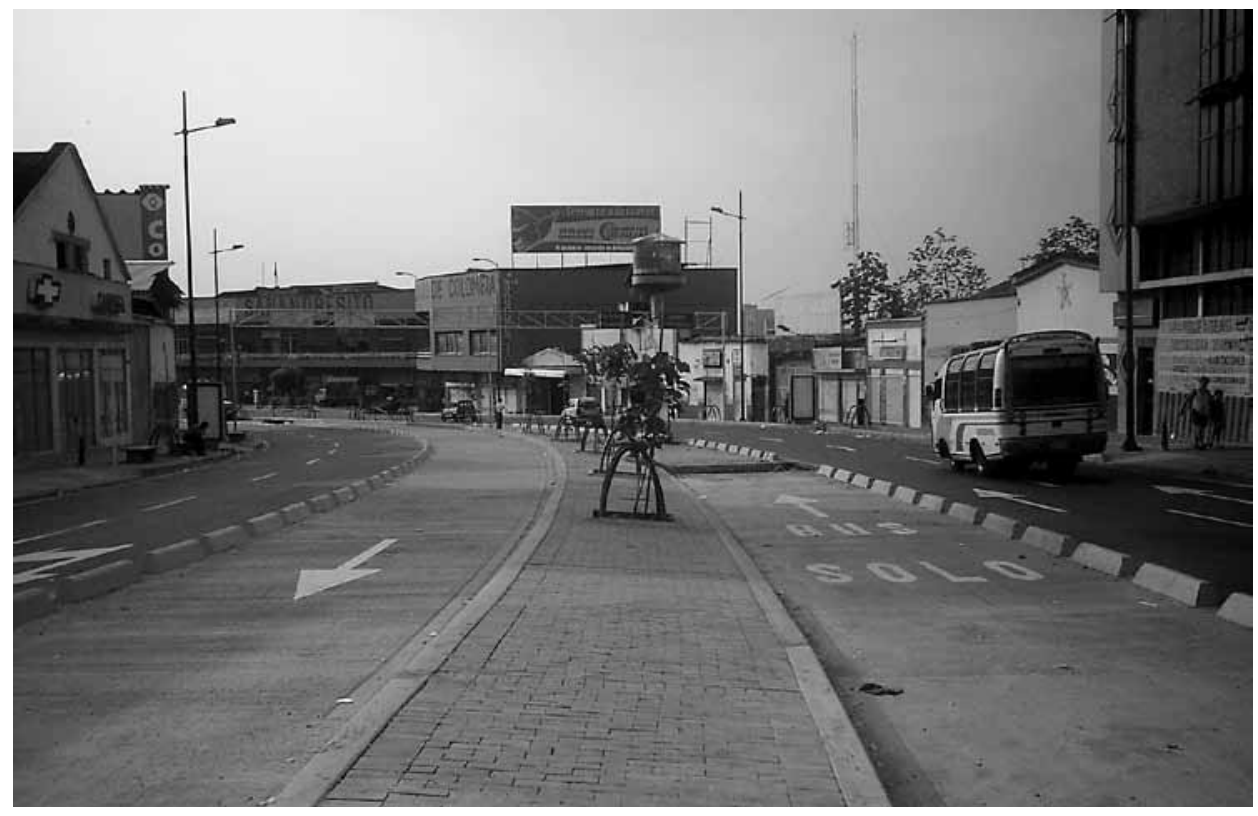

foto 10. Panorámica Carrera 15 a la altura de la Av. La Rosita

\section{Evaluación / Proyección}

El desarrollo comercial a lo largo de los 4 ejes comerciales (en las vías de mayor dimensión y perfil), se constituye en un potencial para el reordenamiento de actividades urbanas de condiciones adecuadas.

El continuo desarrollo de la actividad comercial en el eje de la calle 37, amerita una reformulación de las formas de ocupación del suelo y la generación de espacio público.

\section{VARIABLES: (5) Uso comercial, Flujos vehiculares, Flujos de transporte público (figura 22)}

Al realizar un análisis comparativo y una superposición de las anteriores variables particulares, es posible realizar la siguiente caracterización territorial.

\section{Descripción / Explicación}

Aunque el sector es predominantemente comercial, a lo largo de los principales ejes vehiculares (carrera 15, Av. La Rosita y la calle 45), (Foto 10) se desarrolla la mayor actividad comercial.

En los ejes de flujo de transporte público colectivo, se desarrollan las actividades comerciales más significativas del sector.

\section{Evaluación / Proyección}

El desarrollo comercial a lo largo de los 4 ejes comerciales (en las vías de mayor flujo vehicular y de flujo de transporte público), se constituye en un potencial para el reordenamiento de actividades urbanas de condiciones adecuadas. 


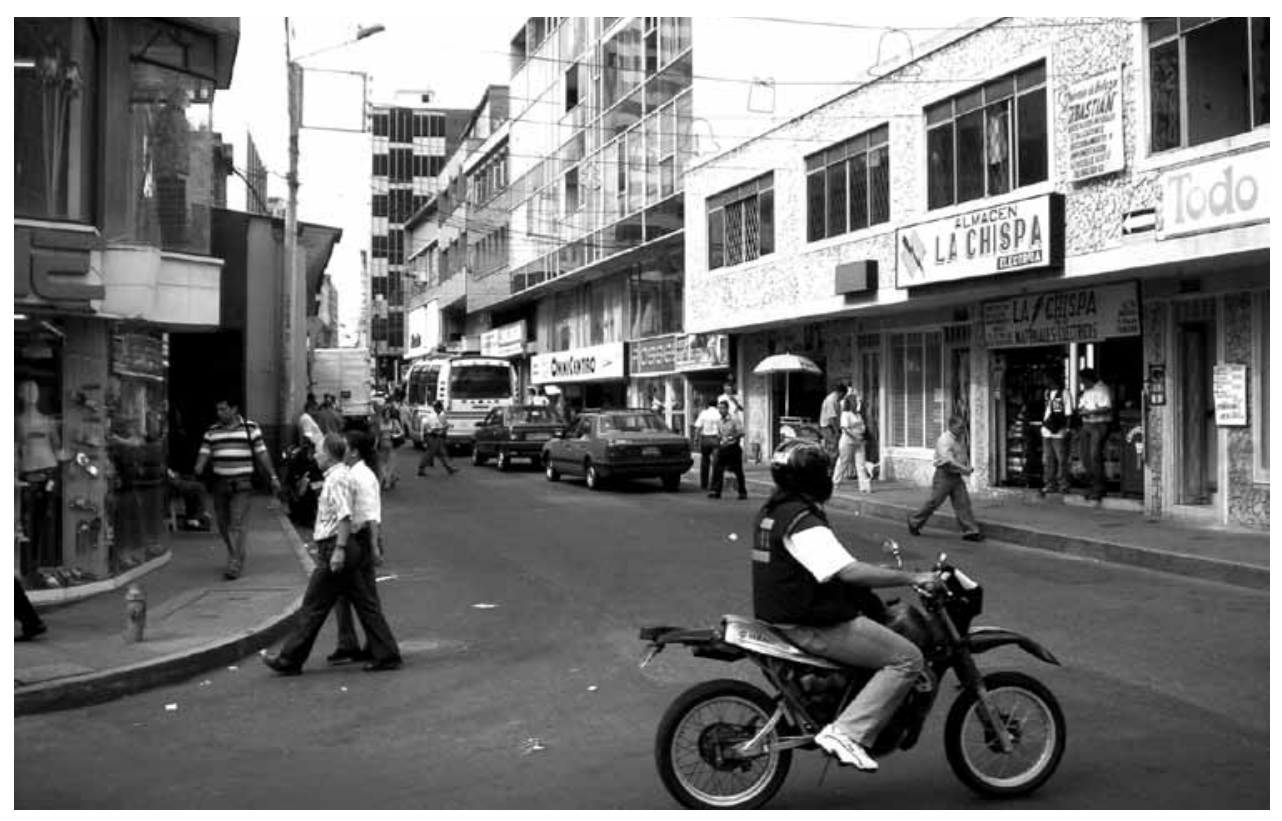

Foto 11. Carrera 17 con calle 37

El desarrollo de la actividad comercial en los ejes de la carrera 15, la calle 37 y la carrera 20 , amerita una reformulación de las formas de ocupación del suelo y la generación de espacio público. (Fotol I)

\section{VARIABLES: (6) Uso comercial, Flujos vehiculares, Puntos críticos}

Al realizar un análisis comparativo y una superposición de las anteriores variables particulares, es posible realizar la siguiente caracterización territorial.

\section{Descripción / Explicación}

El área central presenta la mayor cantidad de puntos críticos, principalmente debido a los altos flujos vehiculares y a la discontinua trama urbana.

En ciertas áreas de los sectores occidental y oriental, se presentan puntos críticos, debido a la congestión vehicular que se genera por la gran cantidad de vehículos que transitan en el sector.

\section{Evaluación / Proyección}

Los altos flujos vehiculares que se presentan a lo largo de los principales ejes viales (carrera 15, Av. La Rosita, carrera 20 y la calle 45), generan una serie de intersecciones críticas, que a su vez se constituyen en indicador para una potencial recualificación de los elementos de la movilidad del sector. 


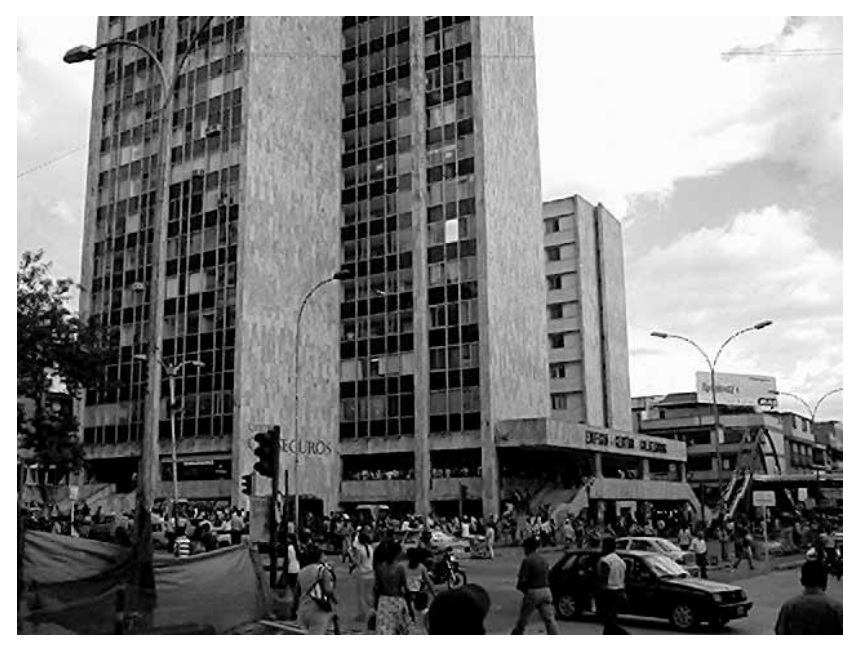

Foto 12. Edificio Colseguro

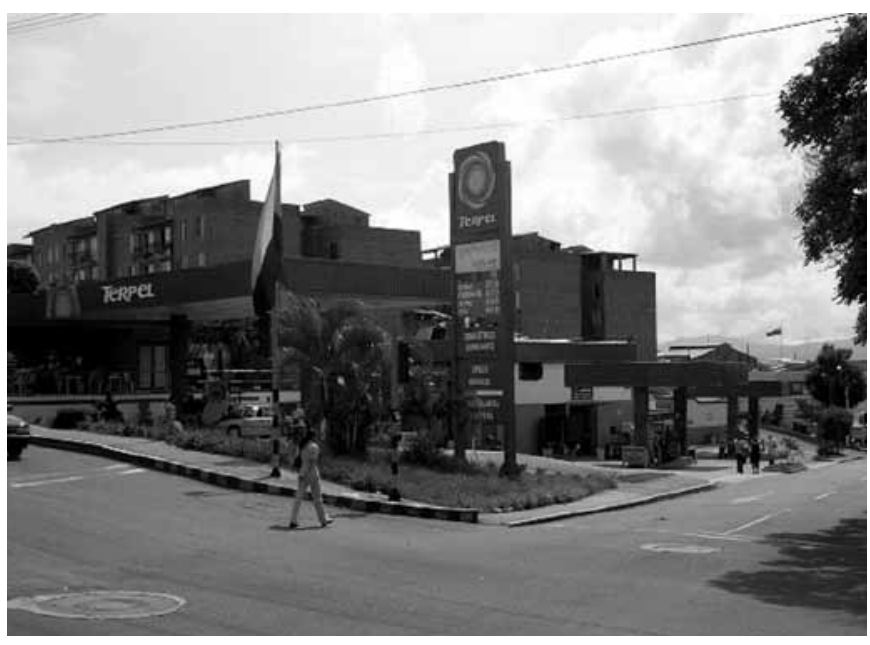

Foto 13. Aspecto de la Avenida La Rosita con Carrera 21.

VARIABLES: (7) Usos del suelo, Flujos peatonales, Elementos de Espacio Público

Al realizar un análisis comparativo y una superposición de las anteriores variables particulares, es posible realizar la siguiente caracterización territorial.

\section{Descripción / Explicación}

Los mayores flujos peatonales de desarrollan en a lo largo de la carrera 15, por ser el principal eje comercial y conector del sector con otras áreas de la ciudad.

Los flujos peatonales que se dirigen hacia la carreral 5 utilizan tanto la calle 37 como las calle 45 y en menor proporción la Av. La Rosita. En sentido norte - sur, los mayores flujos están en las carreras 20,18 y 17.

El parque se constituye en la única área de encuentro y de uso público del sector. (Foto 12)

\section{Evaluación / Proyección}

Los flujos peatonales se desarrollan de manera tangencial al sector, generando un negativo efecto en la calidad del ambiente urbano, lo que sumado a la insuficiencia de áreas públicas, no permiten un adecuado aprovechamiento del suelo.

\section{VARIABLES: (8) Usos del suelo, Dimensión de andenes, Estado de andenes}

Al realizar un análisis comparativo y una superposición de las anteriores variables particulares, es posible realizar la siguiente caracterización territorial. 


\section{Descripción / Explicación}

El espacio público peatonal presenta serias deficiencias tanto por el estado, como por la dimensión de los mismos, principalmente en el área central.

El único sector con un excelente estado y dimensión, es el eje de la carrera I 5 (sometida recientemente a intervenido por el proyecto METROLÍNEA)

Los sectores de la calle 45 y la Av. La Rosita, presentan una dimensión y un estado de conservación de los andenes aceptable, aunque existen áreas críticas. (Foto I3)

\section{Evaluación / Proyección}

El deficiente estado y dimensión de los andenes generan un negativo efecto en la calidad del entorno urbano, lo que no permiten un adecuado aprovechamiento del territorio.

\section{VARIABLES: (9) Dimensión de andenes, Mobiliario urbano, Arborización urbana}

Al realizar un análisis comparativo y una superposición de las anteriores variables particulares, es posible realizar la siguiente caracterización territorial.

\section{Descripción / Explicación}

El área central presenta serias deficiencias por la ausencia de mobiliario y arborización urbana.

La falta de mobiliario y arborización urbana en parte obedece a la dimensión tan reducida de los andenes y las áreas para el uso público.

\section{Evaluación / Proyección}

La usencia de mobiliario y arborización urbana en el sector evidencia la carencia de calidad urbana del sector y la falta de iniciativas públicas en materia de mejoramiento del espacio público peatonal

\section{VARIABLES: (10) Usos del suelo, Invasión del espacio público, Flujos peatonales.}

Al realizar un análisis comparativo y una superposición de las anteriores variables particulares, es posible realizar la siguiente caracterización territorial.

\section{Descripción / Explicación}

En los sectores más comerciales y de mayor flujo peatonal, como la carrera 15, la calle 37, se evidencian los mayores índices de invasión del espacio público. 
La invasión de andenes se debe tanto a la falta de conciencia ciudadana sobre el respeto por las áreas pública, como a la ausencia de control sobre las mismas, y a la falta de áreas especializadas para el estacionamiento o las ventas en el espacio público. (Foto I4))

\section{Evaluación - Proyección}

La invasión del espacio público se constituye en un factor de pérdida de calidad ambiental y urbana del sector.

\section{VARIABLES: (I I) Usos del suelo, Alturas edilicias, Vacíos urbanos}

Al realizar un análisis comparativo y una superposición de las anteriores variables particulares, es posible realizar la siguiente caracterización territorial.

\section{Descripción / Explicación}

Las mayores alturas se ubican hacia los ejes viales principales donde existe una mayor afluencia y actividad, lo que contrasta con una gran área hacia el centro, de menores alturas, tanto de edificaciones de vivienda como de comercio.

En contraste, existen importantes áreas de vacíos urbanos usados como áreas de estacionamiento.

\section{Evaluación / Proyección}

Las bajas alturas existentes en el sector reflejan una notable sub utilización del suelo y de la infraestructura física, por lo que las formas de ocupación no responden a las posibilidades que ofrece el área para el desarrollo de una mejor oferta edilicia.

En contraste, la ubicación de edificaciones de mayores alturas sin un estándar claro de ocupación, son factores que restringen la calidad urbana del sector. (Fotos 15, 16)

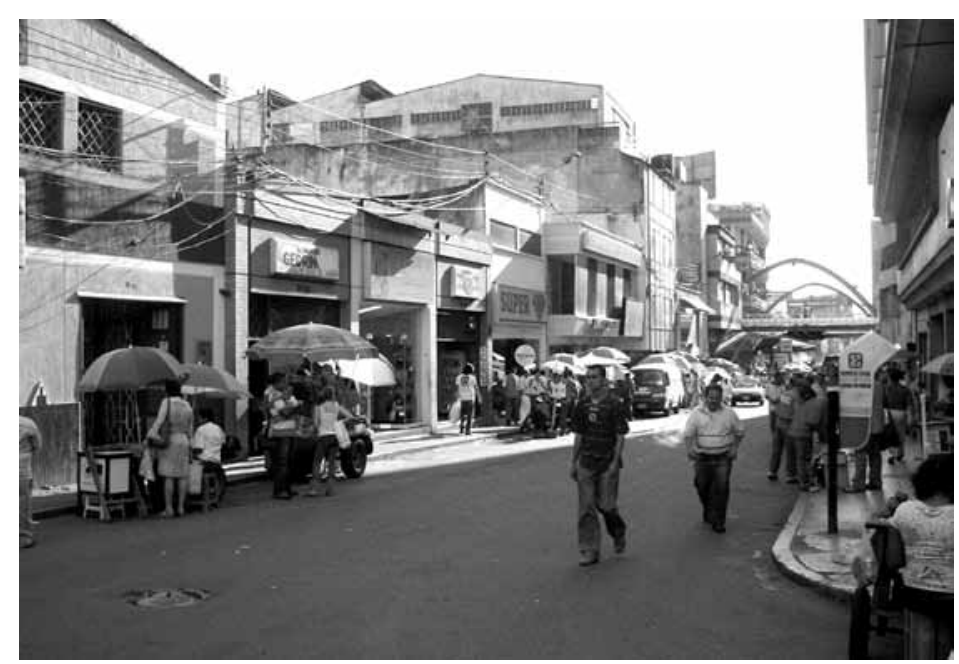

Foto 14. Calle 37 


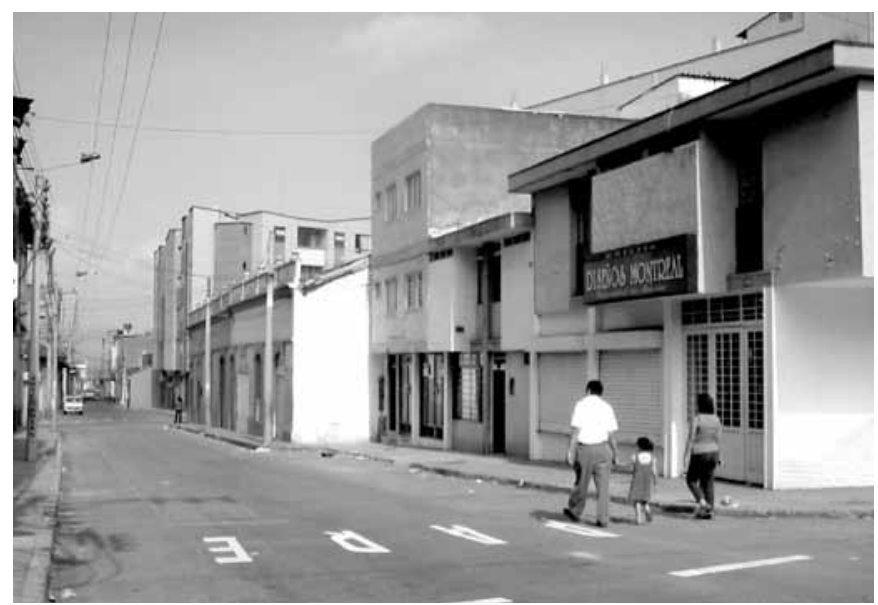

Foto 15 .

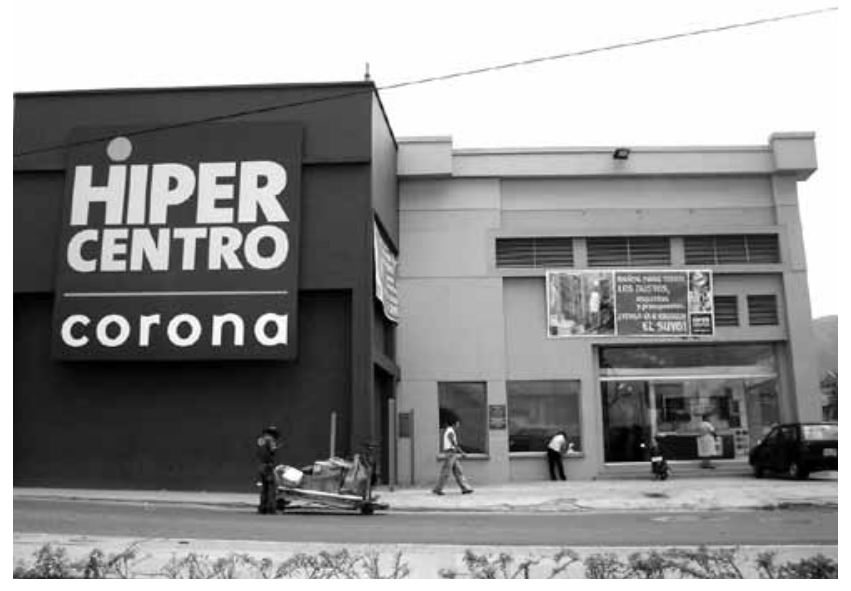

Foto 17

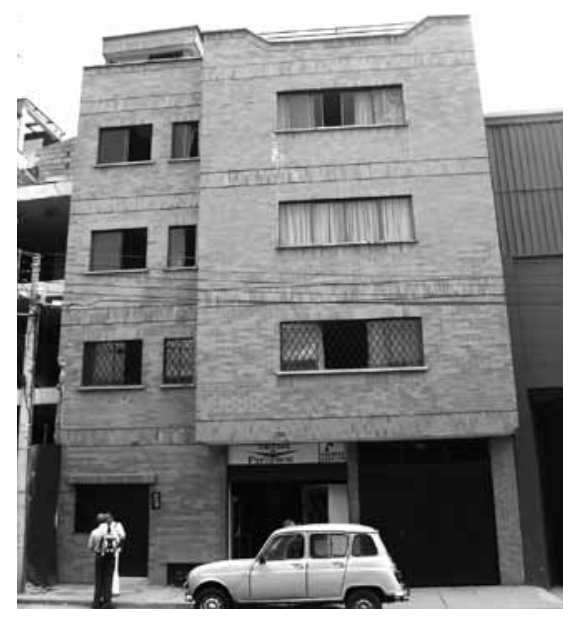

Foto 16.

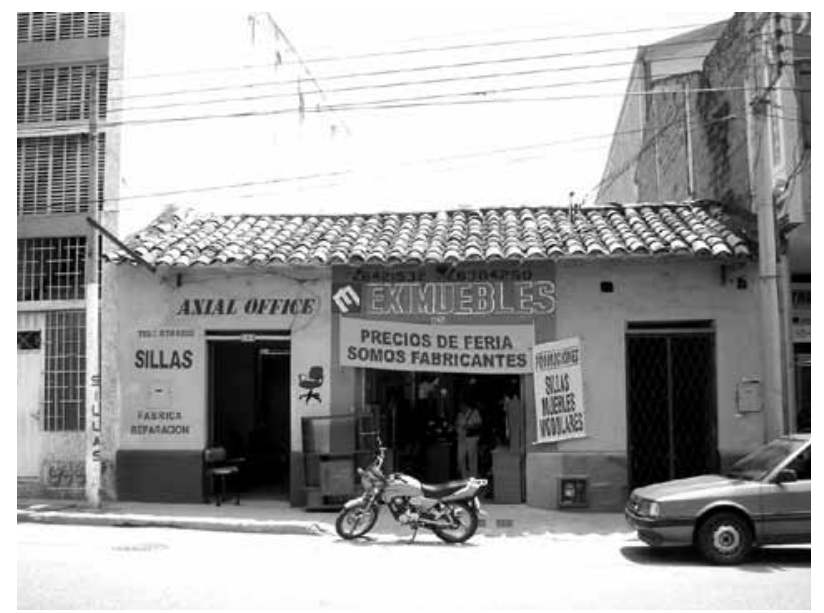

Foto 18.

\section{VARIABLES: (1 2) Uso comercial, Cobertura, Impacto}

Al realizar un análisis comparativo y una superposición de las anteriores variables particulares, es posible realizar la siguiente caracterización territorial.

\section{Descripción / Explicación}

El sector presenta comercio general, predominantemente de cobertura local y zonal, desarrollado en las áreas norte y centro principalmente. Dicho comercio genera un alto impacto debido a la insuficiencia de áreas para su abastecimiento y parqueaderos principalmente.

El comercio de escala urbana y metropolitana se desarrolla en las áreas occidental y sur, con algunos enclaves en el sector oriental (ejes viales principales), lo que genera un gran alto impacto urbano, pero que en algunos casos es absorbido al interior del predio. (Foto 17)

\section{Evaluación - Proyección}

La distribución del comercio de escala urbana y metropolitana, hacia el occidente y el sur, contribuye a la generación de desequilibrios funcionales reflejados en la saturación de la infraestructura física y en las formas de ocupación del suelo. (Foto 18)
Fotos 14 a 18. Aspectos del Sector objeto de estudio. 


\section{VARIABLES: (I3) Uso del suelo, Estado edilicio, Edad edilicia}

Al realizar un análisis comparativo y una superposición de las anteriores variables particulares, es posible realizar la siguiente caracterización territorial.

\section{Descripción / Explicación}

La calidad de las edificaciones, reflejada en los materiales empleados en su construcción y el estado actual de los mismos, es aceptable en la gran mayoría de los casos, sin embargo, existen zonas ubicadas hacia el centro, que presentan un deficiente estado de la construcción.

Debido principalmente al sistema artesanal empleado y a la falta de mantenimiento, existen numerosas construcciones, tanto residenciales como comerciales, con deficiencias estructurales, reflejadas en el deterioro de las fachadas y cubiertas.

\section{EVALUACIÓN - PROYECCIÓN}

El deterioro de las edificaciones, principalmente antiguas, se constituye en factor de pérdida de calidad urbana, y a su vez en un escenario de oportunidad para la recualificación del sector. (Foto 19)

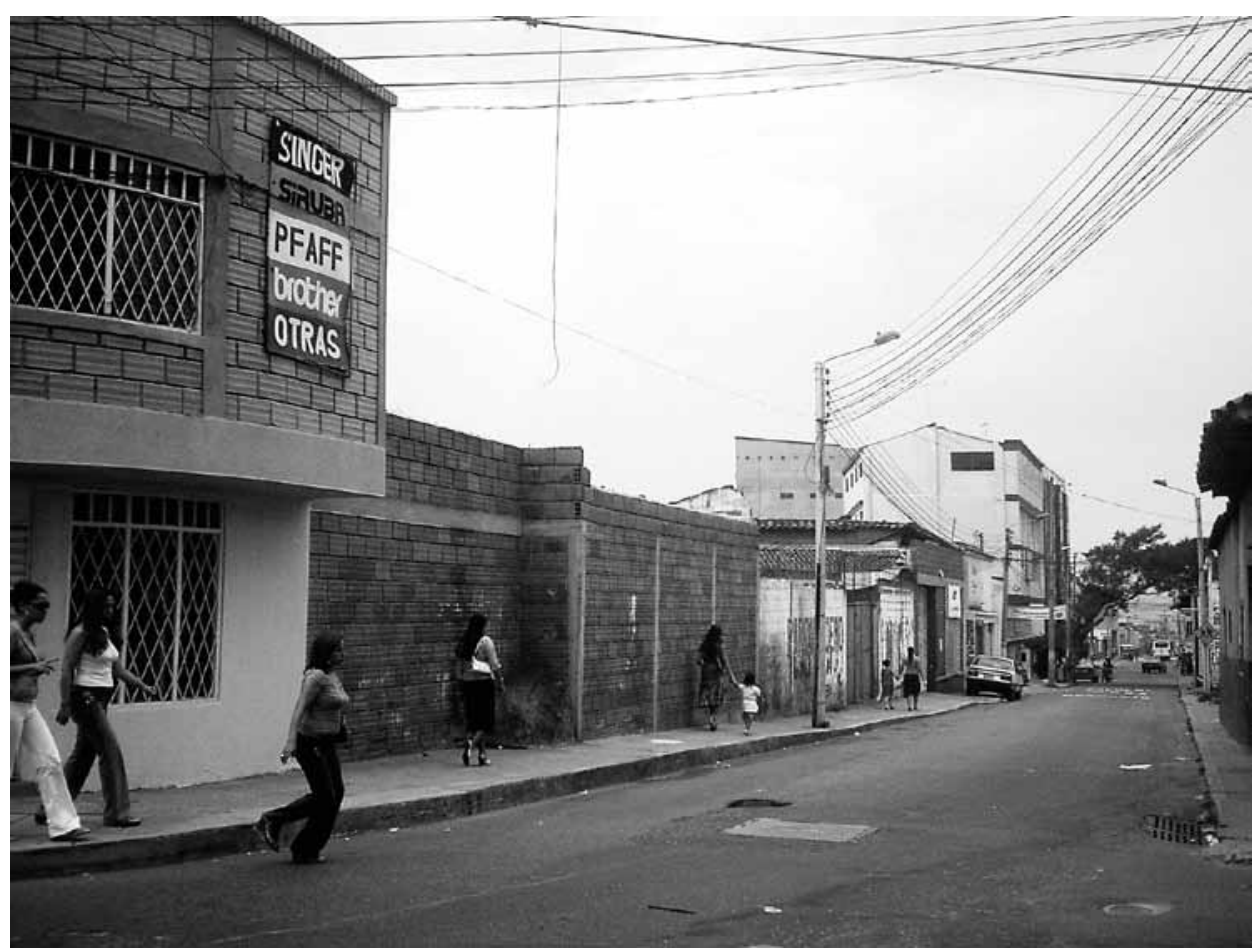




\section{ESTRUCTURA URBANA}

A partir del análisis de las variables específicas y de los grupos de variables, se corroboró la caracterización inicial propuesta:

"El sector se caracteriza por ser un área de comercio general con algunos enclaves de comercio organizado en edificaciones especializadas (almacenes de cadena, híper almacén y centros comerciales), con presencia áreas de servicios, desarrollados en predios de gran tamaño, y escasez de áreas de vivienda, con algunas edificaciones antiguas construidas hace más de 100 años, con deficiencia de espacio público y rodeadas por importantes ejes viales, que limitan con el centro histórico y financiero de la ciudad"

\section{CONCLUSIONES}

Desde el ámbito de la gestión se identificaron varios proyectos que plantean el problema de la centralidad desde la perspectiva de la renovación y de la recualificación del espacio público, pero la resultante de esos proyectos no permite ver una línea de actuación coherente y un plan estratégico que direccione el proceso en el largo y mediano plazo. Las propuestas san sido de orden coyuntural y estrategias de gobierno muy puntuales sin que se pueda articular los proyectos como una totalidad.

En el Plan de Ordenamiento Territorial se evidencia la formulación de la necesidad de intervenir en el área central, pero es claro que es un documento general y limitado que obliga al desarrollo de proyectos de investigación puntuales para abordar estrategias de investigación específicas, tomando como parámetros lo establecido en la Ley 388 , como los planes parciales.

A partir de lo establecido en el Plan de Ordenamiento Territorial, se hace evidente el desconocimiento de los procesos de ocupación del territorio y su transformación histórica, ya que la formulación de estándares e indicadores urbanos (índices de ocupación y construcción, tratamientos urbanos y usos del suelo), no responden a las actuales dinámicas tanto de saturación de actividades comerciales, como de ausencia de vivienda a escala (desarrolladas en altura), en el sector.

Se confirmó la hipótesis de que: "la trama urbana del sector posee una vialidad asimétrica, en la que los ejes potentes: Carrera 15, la calle 45 y la Avenida la Rosita, marcan la conectividad de los grandes proyectos en un sentido periférico, al tiempo que hacia su interior la vialidad es conflictiva, acentuado por la ausencia de espacio público", ya que el sector está enmarcado los principales ejes viales a escala urbana: en sentido longitudinal (carrera 15), y en sentido transversal la calle 45, en contraposición a una malla interior estrecha y ausente de espacio público y áreas de circulación peatonal, condicionada tanto por una red histórica de caminos, cómo de las formas de lineales de ocupación del territorio.

Se confirmó la hipótesis de que: "la trama urbana fue originalmente condicionada por dos elementos, los ejes de caminos y sus condiciones geográficas, especialmente los producidos por las pendientes de la cañada de la Quebrada Rosita, ello definió una estructura irregular, caracterizada por manzanas de gran tamaño, en donde sus predios son escasos y unas manzanas de menor tamaño, en donde la segmentación predial es notable", ya que la conformación de una trama urbana irregular y manzanas de gran tamaño (hacia el sur), y un trazado discontinuo y conformado por manzanas de formas medianamente irregulares 
hacia el área central, se debe a la configuración geográfica y a las formas de ocupación histórica del sector.

En el sector acotado se evidencia la presencia de importantes áreas con o sin significativos desarrollos edilicios una densificación de proyectos de comercio organizado de gran tamaño, sobre los bordes Norte, Calle 37; borde occidental (carrera I5) y sur occidental (Almacén Éxito) que han concentrado las inversiones en detrimento de remanente central degradado.

El sector está ocupado por uso residencial de baja calidad, directamente relacionado con actividades comerciales no organizadas e informales, generadas por conflictos de uso, en especial en el sector central.

Es evidente que el alto nivel de conflictividad que genera el sector en su interior, incide de manera directa en el contexto general del área central, $y$ amerita procesos la planificación de procesos de renovación urbana que contemplen estrategias, programas y proyectos de ordenamiento y sostenibilidad urbana.

\section{BIBLIOGRAFÍA}

ÁLVAREZ, Fuentes Jaime, RUEDA Gómez Néstor José. Historia urbana de Bucaramanga 1900 - 1930 Ed. SIC, UIS, CER, 2001

BAYONA Chaparro José Alejandro, Foro: Por una Colombia Bien Gobernada 2008 - 201 I Santa Marta, 15 de Abril de 2008

DANGOND Gibsone Claudia, JOLLY Jean-FranÁois, MONTEOLIVA Alejandra, NIÑO Soto. Alexánder. UNA REFLEXIÓN CRÍTICA SOBRE LOS LINEAMIENTOS DEL DOCUMENTO CONPES 3305. En: Pap. Pollt. Bogotá. (Colombia), Vol. II, No. I, 47-68, enero-junio 2006, ISSN 0I22-4409

FACULTAD de Arquitectura, (2002), Documento de las Primeras Jornadas de Investigación en Arquitectura, Universidad de la República, Montevideo, Uruguay.

GOBIERNO de la Ciudad de Buenos Aires, (2000), Plan Estratégico Zona Sur, Secretaría de Medio Ambiente y Desarrollo Regional, Buenos Aires, Argentina.

GÓMEZ, Alejandro, Seminario de Planificación Urbana: Plan de Ordenamiento Territorial, Lineamientos conceptuales, metodológicos y normativos, Capítulo Síntesis Metodológica, Bucaramanga, en elaboración.

GOUESET, Vincent. BOGOTÁ NACIMIENTO DE UNA METRÓPOLI la originalidad de crecimiento urbano en Colombia. Ed. Tercer Mundo Editores, observatorio de cultura urbana, CENAC, IFEA y FEDEVIVIENDA, Bogotá 1998

IGAC, (1996), Guía Metodológica para la Formulación del Plan de ordenamiento Territorial Urbano, Santafé de Bogotá, D.C., Primera Edición. 
KULLOCK, David, (1995), Planificación Participativa y Hábitat Popular, U.B.A., Buenos Aires, Argentina.

MESÍAS González, Rosendo y Suárez Paredón Alejandro, (1997), Los Centros Vivos, Centro de Vivienda y Estudios Urbanos, Lima. Perú.

MINAMBIENTE, (2004), documentos de renovación urbana, www.minambiente.gov.co, Bogotá

MOYA, Luis, (200I), El proyecto del Espacio Vacío, Publicación de ETSAM - Universidad Politécnica de Madrid, España.

OSTROWETSKY, Silvia, Artículo las Centros Urbanos, www.memoria.com.mx

PARODI, Aníbal, (2002), Relatoría mesa de trabajo No. I, Documento de las Primeras Jornadas de Investigación en Arquitectura, Universidad de la República, Facultad de Arquitectura, Montevideo, Uruguay.

PRIETO, Castillo, (I993) Educar Con Sentido, EDIUNC, Mendoza, Argentina.

RUEDA, Gómez Néstor José. Bucaramanga: paradojas de un ordenamiento urbano. USTA, 2003

Proyectos 2006, Renuevan el centro de Pereira. En: Metro cuadrado. com. file://G:/ proyecto\%20centro/pereira\%20I.htm

TROITIÑO, Miguel Ángel, (2000), Revista Perspectivas Urbanas, Artículo Renovación urbana: dinámicas y cambios funcionales, Colegio de Arquitectos de Aragón, España.

. (2003), Artículo renovación urbana: dinámicas y cambios funcionales, universidad politécnica de Cataluña, www.etsav.upc.es, España.

VALENCIA, Jaramillo Jorge. Isaza Giraldo Fabio (editor) Las Reformas urbanas en Colombia. En: Reforma Urbana y Desarrollo Social. Ed. CAMACOL, 1989

VARGAS, R. Jaime. Corrupción en Pereira. En: Revista de prensa. file://G:/proyecto\%20 centro/corrupcion-en-pereira.html 